\title{
Evaluating the Potential Use of Tidal Energy: A Study of Different Regions in Kuwait
}

\author{
Saad Abdullah Alshatti, Mohammed Salem Alsubai'e
}

Specialist Trainer (G), The Public Authority for Applied Education and Training, University of Arab Academy for Science, Technology and Maritime Transport, KUWAIT

${ }^{*}$ Corresponding Contact:

Email: taqwagdah88@gmail.com

\begin{abstract}
This Study is based on Statistical Data of Tidal Waves in the Different Regions of Kuwait. Nowadays, Kuwait city is considered a good example for the countries that characterizes with an essential rate of exhaustion of energy. This in turns results in a substantial increase with need of immaculate and renewable energy obstetrics origins that can be used in generating electricity. This Paper aims to estimate the possibility for employing tidal energy in Kuwait city according to statistically collected data about tidal waves in several areas. Statistics associated to current velocity of water were gathered from Kuwait Institute for Scientific Research. Additionally, Civil Aviation Meteorological Department was managed to be appropriate for obtaining information about current velocity of water. The obtained results in this paper showed that there is a great possibility to use resources of renewable within Kuwait to achieve the demands of energy. Also, the results shows that Plants of tidal power are built within different locations, and the MENA area still lacks to tidal power plant, where that the lone reported plant of the power via tides is the that reputable through an Israeli company called WERPO.
\end{abstract}

Key words:

Renewable Energy, Current Velocity, Tidal Waves, Tidal Energy, Tidal Plant, MENA Region, Kuwait

$12 / 27 / 2018$

Source of Support: None, NoConflict of Interest: Declared

This article is licensed under a Creative Commons Attribution-NonCommercial 4.0 International License.

Attribution-NonCommercial (CC BY-NC) license lets others remix, tweak, and build upon work non-commercially,

and although the new works must also acknowledge \& be non-commercial.

\section{INTRODUCTION}

With rising economic growth, inhabitants and civilianization in Kuwait city, there are usually increased energy requirements. Kuwait city is an example for the countries that characterizes with a vital energy exhaustion rate. This in turns results in a significant raise within the requirement of renewable and immaculate energy obstetrics origins for producing electricity. All over the world, using the origins of renewable energy increases by $3 \%$ yearly and the usage of those origins within electricity obstetrics operation is predicted to reach $23 \%$ in 2035 compared to $18 \%$ during 2007 . An example for the sources of renewable energy that is extensively obtainable within Kuwait city is the energy sources 
of the seas. Usually, seas characterizes with a broadly, enormous and idle energy origins in flow shapes of fluid such as, currents, tides and waves that in turns common as salinity gradients, hydrokinetic shapes as well thermal. Different methods are adopted for energy eliciting operation from different origins such as, Tidal power (dike or dam), Ocean Thermal Energy Conversions (OTEC) and Wave power (Kinetic hydropower). From these shapes of renewable energy, tidal energy seems to be as the orderly and expected a shape to be used as a useful energy alternative in Kuwait city.

\section{Aims AND OBJECTIVES}

This paper aims to evaluate the potential of exploiting the tidal energy within Kuwait state depending on statistics about tidal waves in the several regions. The following objectives should be applied in order to reach paper aims:

- $\quad$ To select the best turbine type based on its performances.

- To analyze the main tidal current features in Kuwait through statistical data, which are given by "Kuwait Institute for Scientific Research (KISR)".

- To assess the probability of utilizing alternative models according to the provided tidal current properties.

- To investigate the tidal turbines performances in term of environmental impact, sustainability, in addition to economic field.

\section{MetHodologY}

The followed methodology in this paper is based on analyzing the tidal data according to a theoretical model so that the paper's goals are achieved. Two location are considered for data collection process and one location is then selected as the best one. Different types of information are included, which are; Direction (deg), Hourly time, Direction (deg), Height $(\mathrm{m})$, Period (sec), Tidal Current (cm/s), Wind Speed (m/s) and Tidal Direction (deg) Water Level (m).

Energy Analysis will be performed within the selected location beside Bubyian Island in Kuwait city then followed by selection and investigation of the model and the using ANSYS and Soild Work software. The process of model selection depends on blade analysis and selection besides the selection and the analysis of diffuser. The analytical procedure had been carried out by software using attack angle and tip speed ratio besides additional essential parameters.

\section{RESULTS AND DISCUSSION}

Here, the results obtained after completing all previously mentioned stages are discussed and analyzed in details.

\section{Accessible Energy Analysis}

Two locations had been considered with different latitudes and longitude. Each location is individually analyzed and a comparison is then held between the two location to choose the optimal and the more appropriate one for installing the tidal turbine depending on the particular data from KISR within Kuwait state.

\section{Analysis of First Location}

The recorded data at first site contains hourly-recorded values for the tidal speed and the tidal height. MATLAB software is used in plotting the recorded data as shown in below in 
Figure 1. As shown, the tidal current speed is plotted along one year beginning from $1 / 1 / 2015$ to $1 / 1 / 2017$ (Based on the available data about tidal current speed), where the average speed was found to be around $0.369 \mathrm{~m} / \mathrm{s}$, which in turns low speed to be exploited for producing of tidal power turbine.

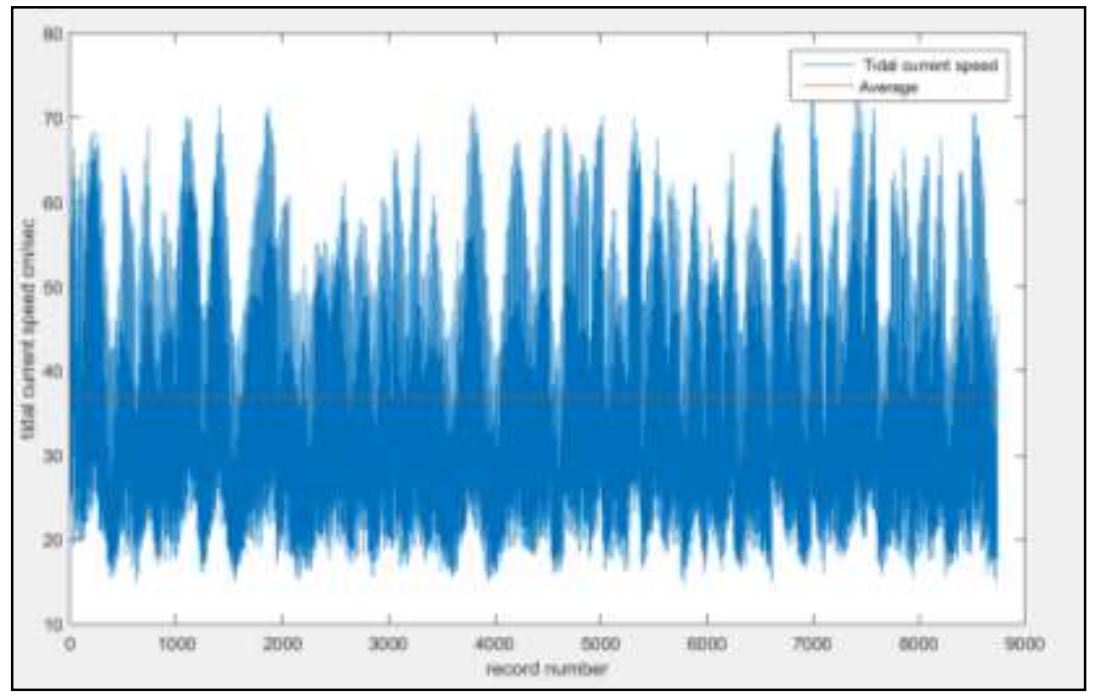

Figure 1: Tidal current Speed

The histogram corresponding to the deliberate tidal speed is illustrated in Figure 2, it can be obviously noticed that the largest values recorded for the tidal current lies within $0.2-0.5 \mathrm{~m} / \mathrm{s}$. It can be also observed that the maximum attained frequency is 550 at speed of $0.6 \mathrm{~m} / \mathrm{s}$.

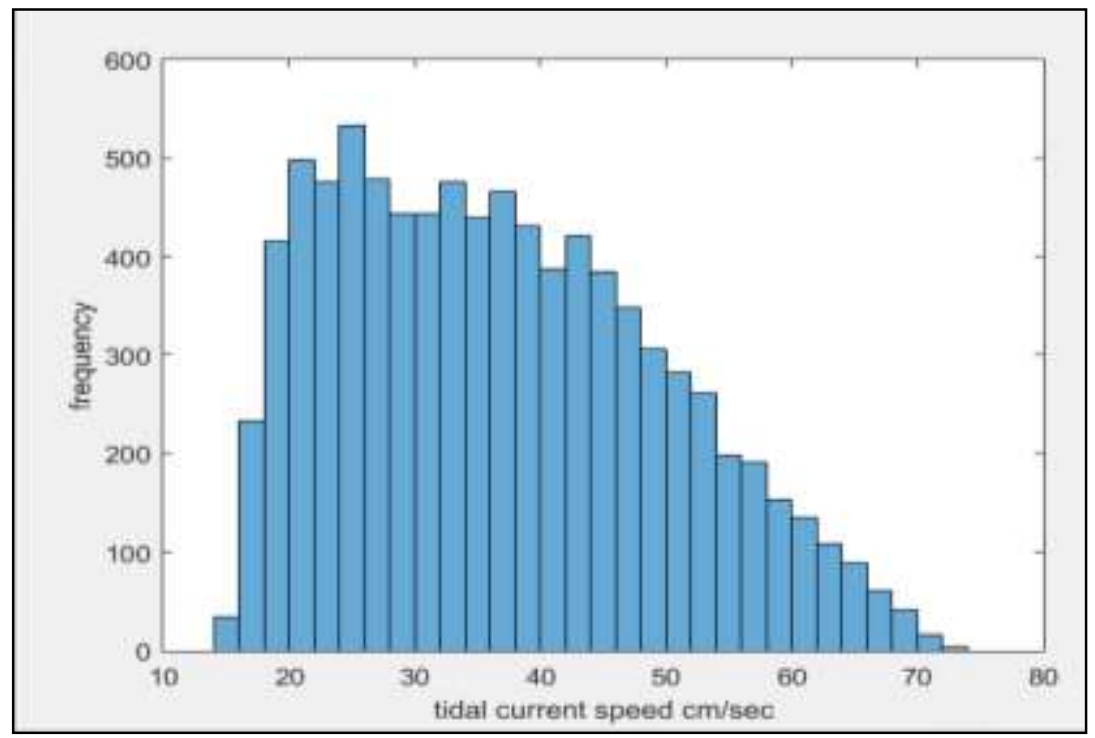

Figure 2: the distribution of frequency for the speed of Tidal current

Three tides can be introduced every day, which are; T1 $=0.1 \mathrm{~m}, \mathrm{~T} 2=.03 \mathrm{~m}$ and T3=0.4m as Figure 3 illustrates. 


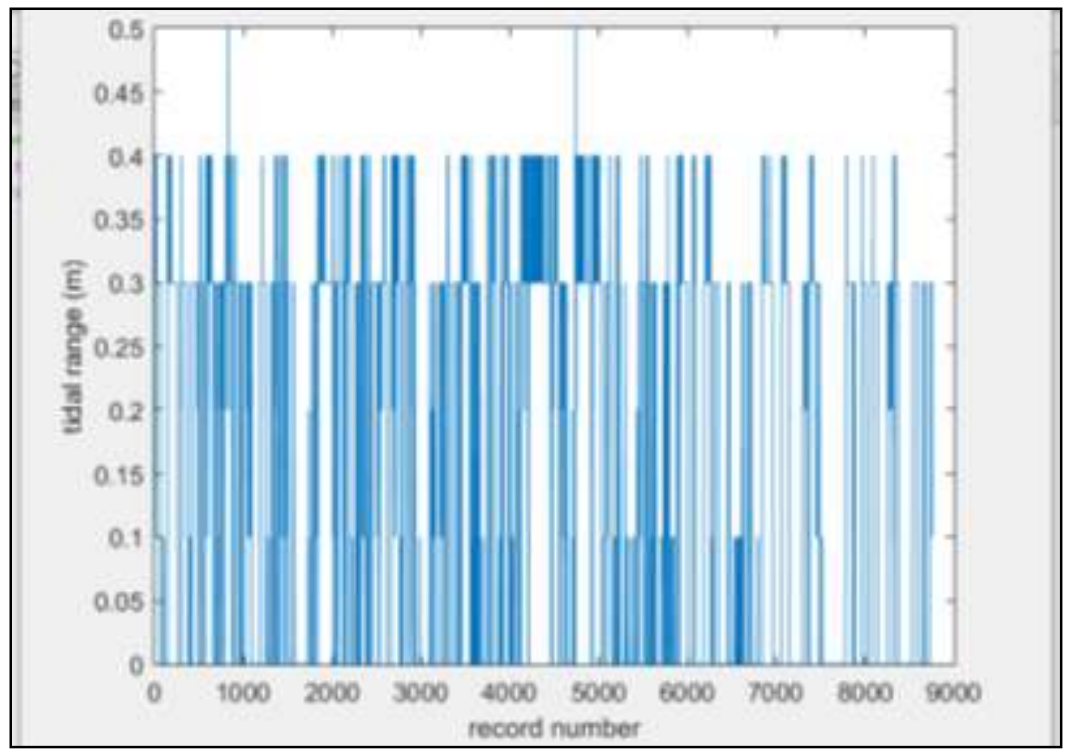

Figure 3: Illustration of Daily tides

The tidal height for three considered daily tides is illustrated in Figure 4 as recorded at the first site especially the recorded tides height each hour based on the attained data. Additionally, there are three values that have been recorded for the waves' height as allotment of frequency as exposed in Figure 4. It is obvious that the highest frequency value is achieved at height $=0$ and then $0.3 \mathrm{~m}, 0.4,0.1$ and the minimum recorded height value of the wave $=0.2 \mathrm{~m}$.

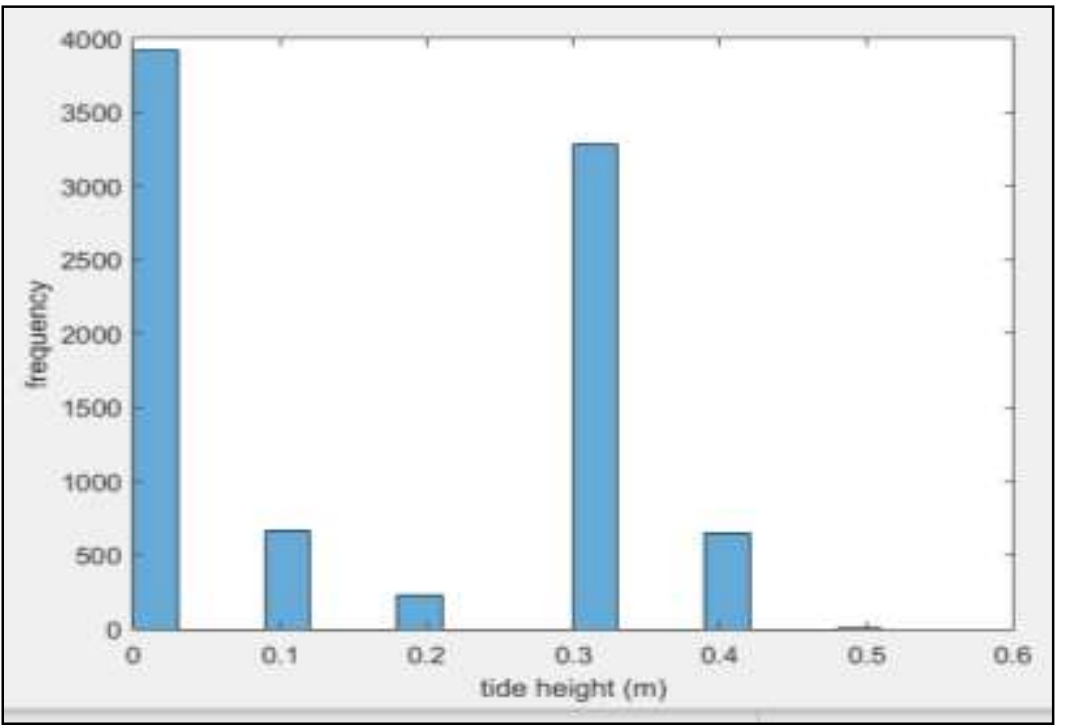

Figure 4: Distribution for the frequency of Wave Height

As well, the Kinetic energy of tides for each record is calculated for the purpose of data plotting as illustrated below within Figure 5. As exposed, the maximum frequency value was attained at $10 \mathrm{~J} / \mathrm{m}^{2}$ of kinetic energy with around 1400 records. 


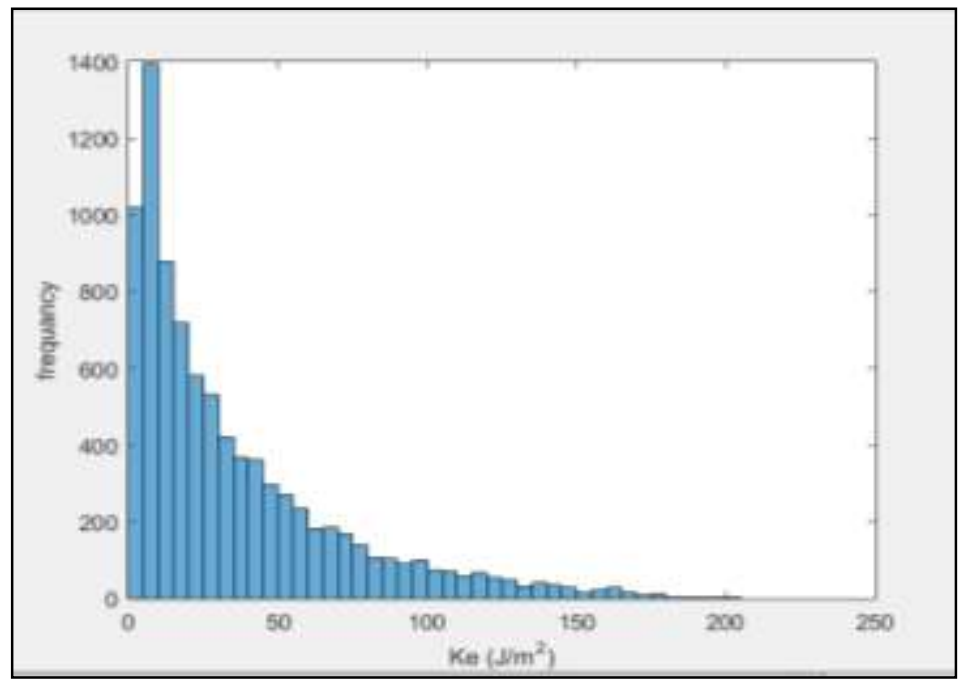

Figure 5: Distribution of Frequency for accumulative Kinetic energy throughout a year $/ \mathrm{m}^{2}$

\section{Analysis of Second Location}

The tidal current speed that has been recorded at the second selected location throughout one year is illustrated in Figure 6. It is observed that the average speed at first selected location seems to be greater than one recorded at first selected location, which in turns considered an advantage for the second location when compared to first one. The average speed of tidal current recorded at second location is 0.403 , which is superior by $10 \%$ than the value recorded value at first location.

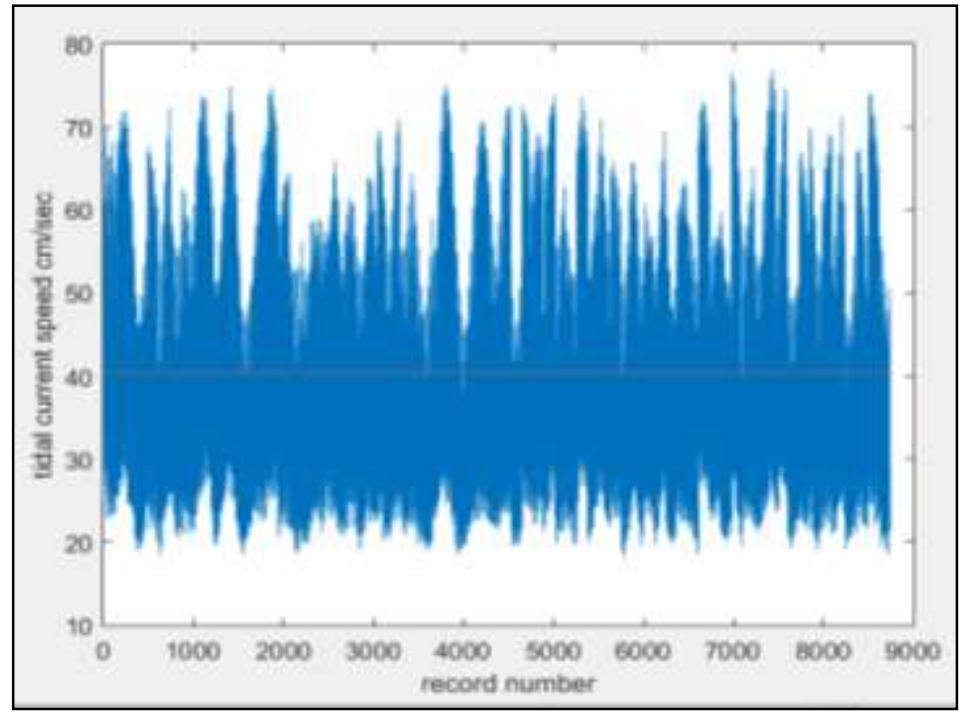

Figure 6: Values of Tidal current speed for the second location

Furthermore, the frequency value for the tidal current speed is plotted as shown in Figure 7 where that value of the maximum frequency has been recorded within a current speed range between $(0.2-0.45 \mathrm{~m} / \mathrm{s})$. 


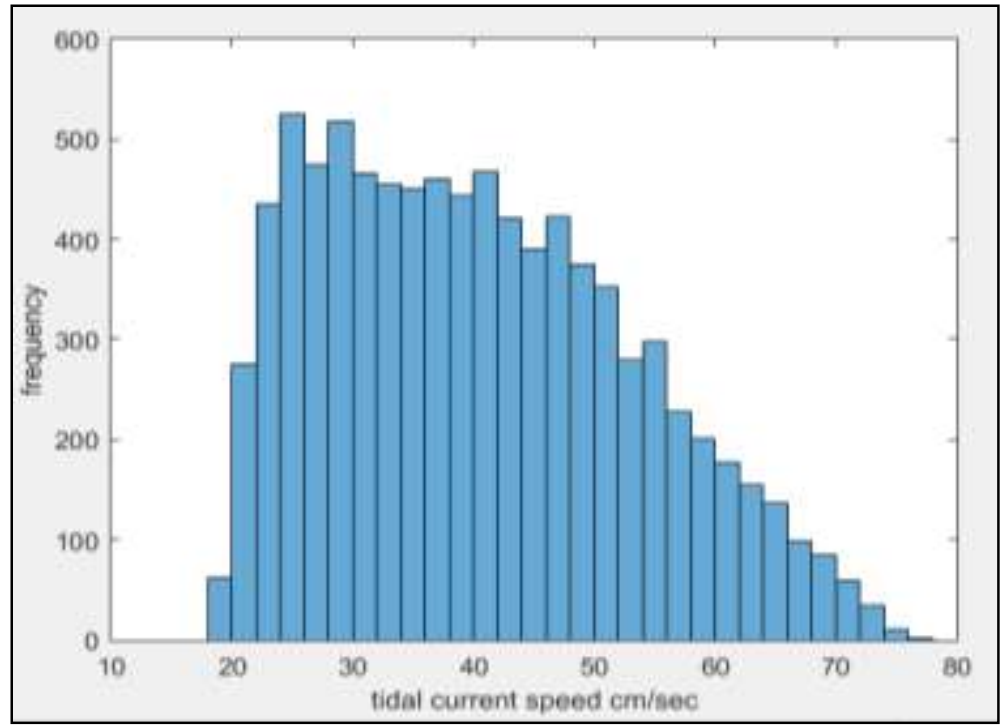

Figure 7: Distribution of Frequency for the speed of tidal current at second location

Figure 8 illustrates the plotted tidal range, which have three recorded tides; which are; $T 1=$ $0.1 \mathrm{~m}, \mathrm{~T} 2=.03 \mathrm{~m}$ and $\mathrm{T} 3=0.4 \mathrm{~m}$ as illustrated below.

According to the daily tides figures that were obtained for the two considered locations, it clear that the height of the tides at both locations are approximately similar.

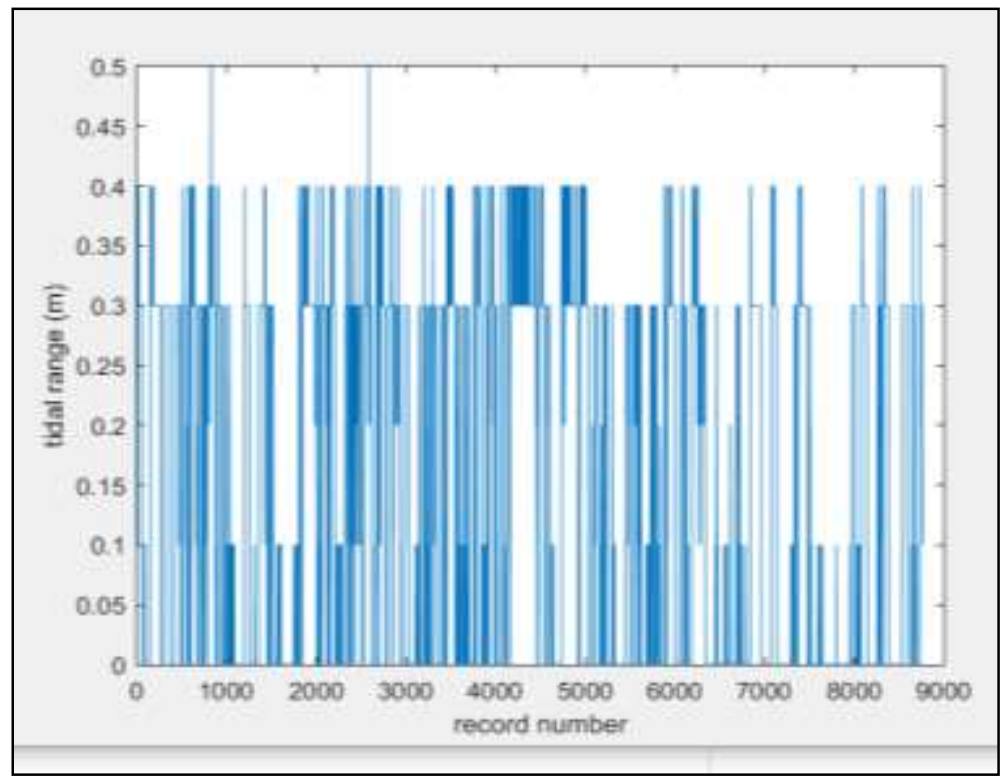

Figure 8: daily tides for the second selected location.

Figure 9 shows the histogram for the heights of the tides, which records the maximum value of frequency for diverse heights, which are; 0, 0.3, 0.4, 0.1, and 0.1 respectively. Approximately, the total records number $=8760$. 


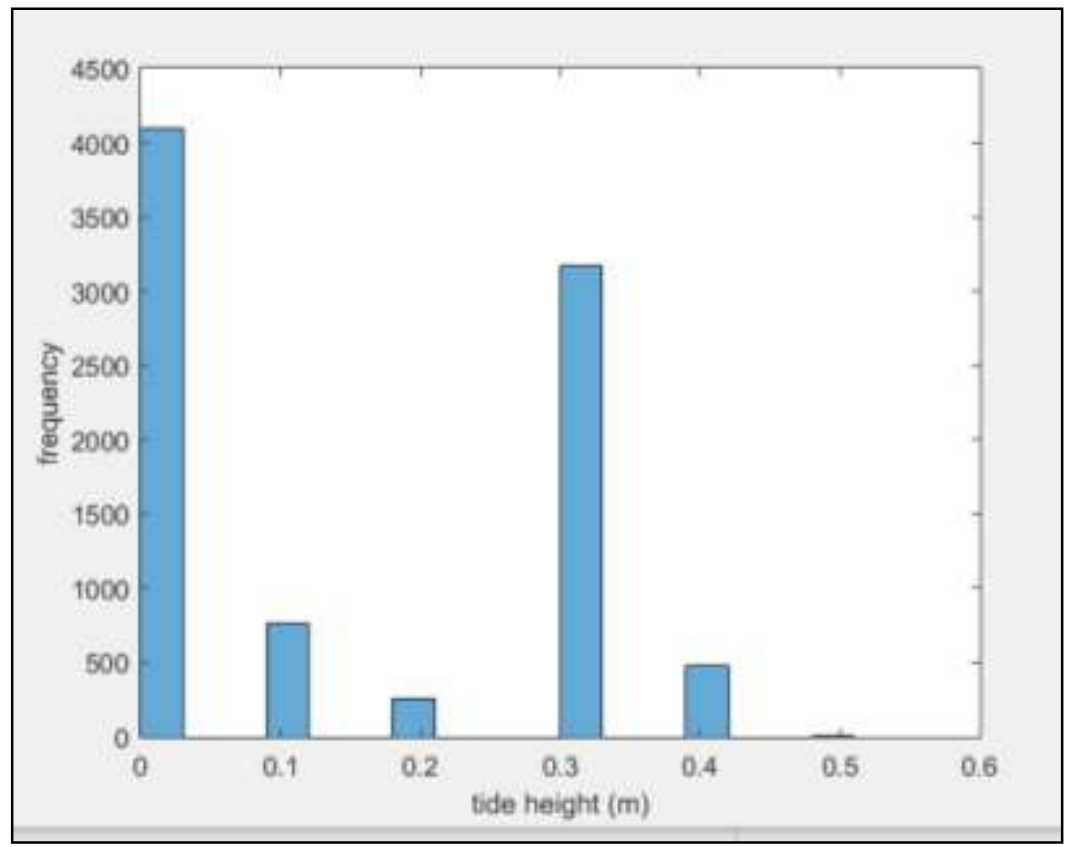

Figure 9: Distribution of Frequency of wave length recorded every day

The analysis of kinetic energy for a second location calculated for the diverse records is illustrated in Figure 10. Additionally, it is depicted when the records number for first location is compared with first selected location at kinetic energy $=0$. It is obvious that the first site records number is greater than recorded one at second site.

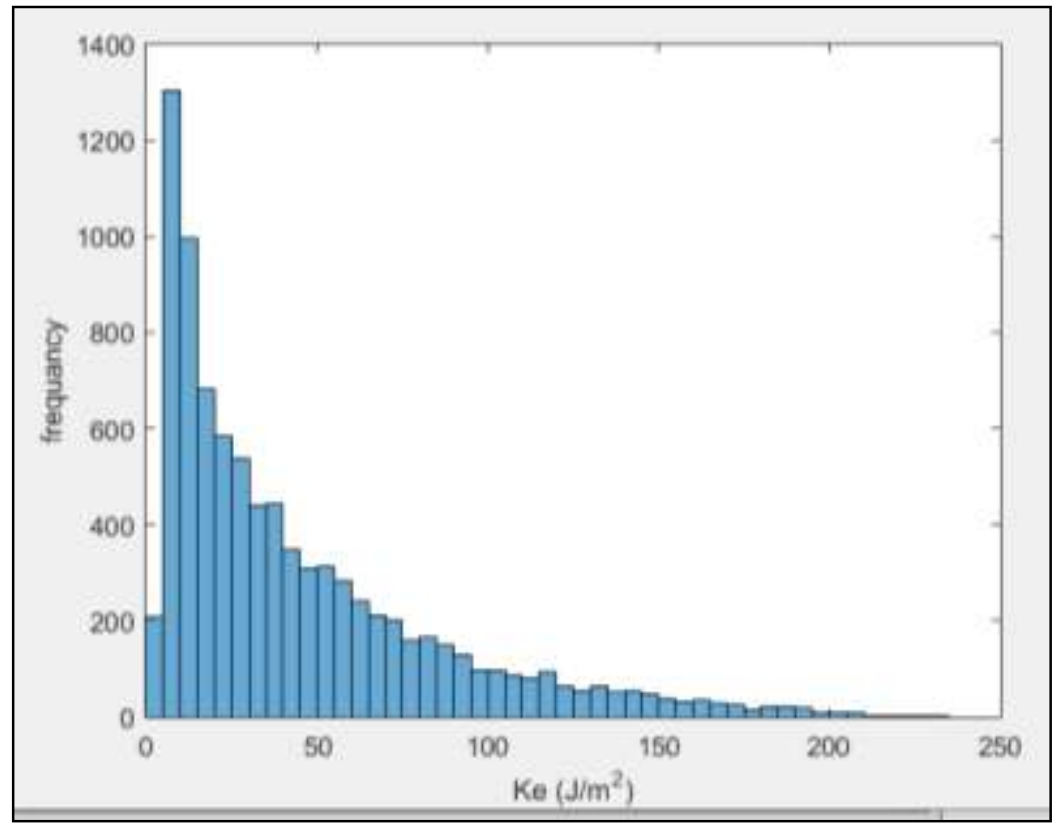

Figure 10: Distribution of Frequency for accumulative kinetic energy 


\section{Comparison between Two sites}

Kinetic energy for both locations is compared in this section in order to decide the most excellent location. As it is noticed, the first site kinetic energy is $4.8455 \mathrm{e}+05 \mathrm{~J} / \mathrm{m}^{2}$ and second site kinetic energy is $6.3018 \mathrm{e}+05 \mathrm{~J} / \mathrm{m}^{2}$.

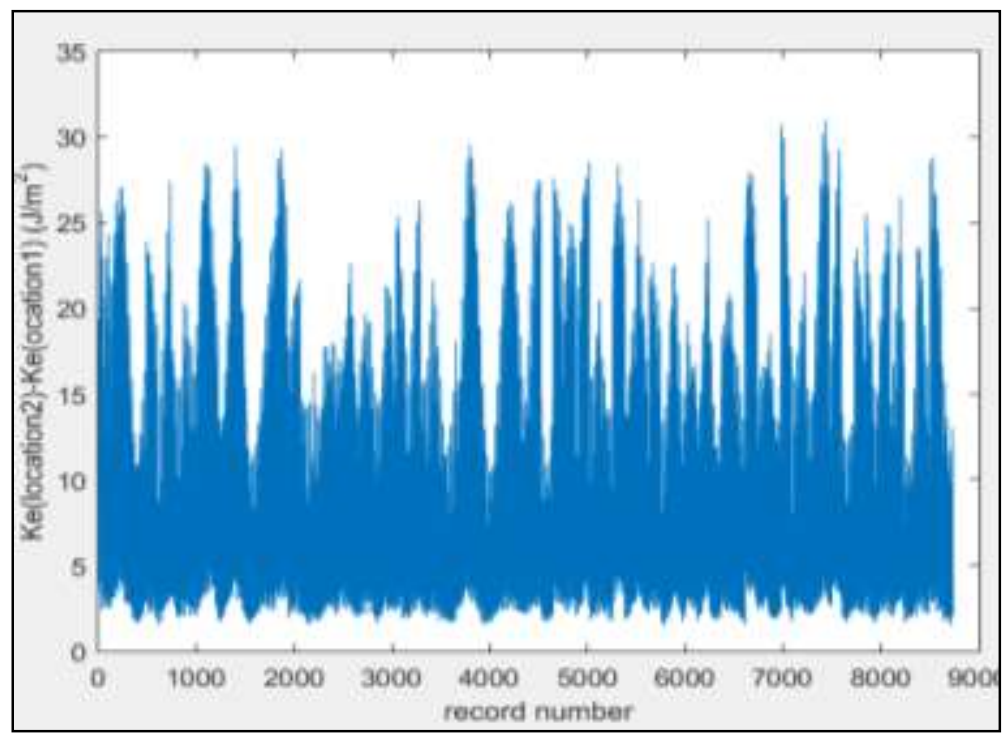

Figure 11: Kinetic energy comparison among the two selected sites

Also, Figure 11 illustrates the obtained kinetic energy difference between the two selected locations. It is obvious that all the kinetic energy values for first and second locations are all greater than zero line (positive values). Consequently, it is a clear that the kinetic energy for the first chosen site is smaller than second site kinetic energy and this result provides a sign about the best location between first and second selected locations.

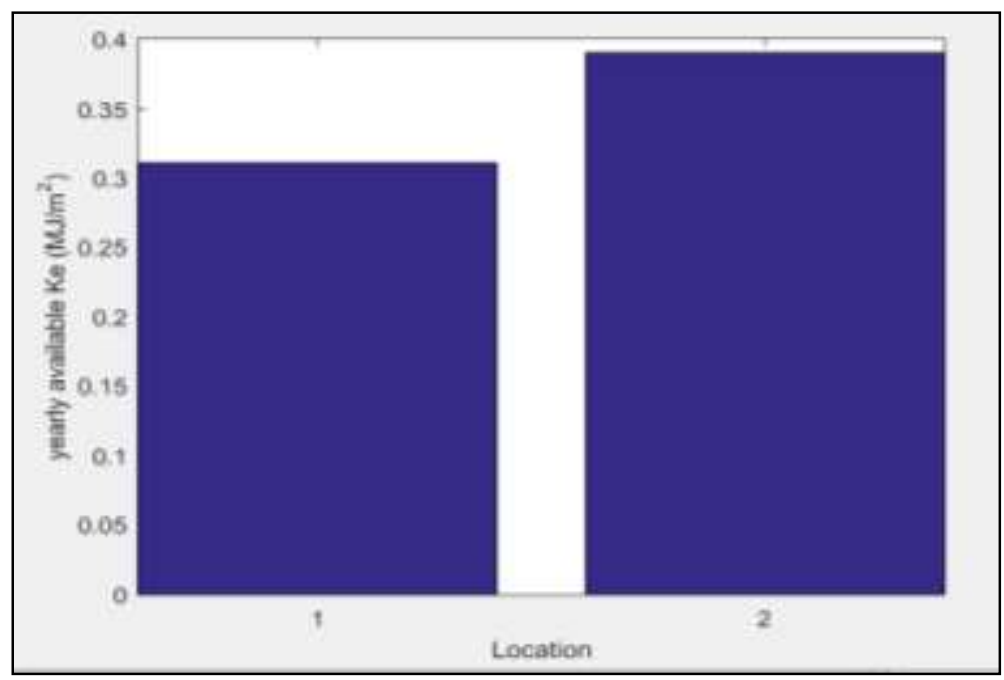

Figure 12: obtainable kinetic energy for the two locations for each year 
As stated earlier, the kinetic energy summation at the first selected site throughout one year is three MJ is illustrated in Figure 12. Additionally, the kinetic energy summation for the second selected site throughout one year is four MJ. It is obvious that the second site has larger kinetic energy summation compared to the first site, which forms another benefit for the second site at the expense of the first selected site.

\section{Model selection}

\section{Blades selection}

For the selected location, the depth of water is between (20 and $25 \mathrm{~m}$ ) and diameter value of the rotor is equal to $5 \mathrm{~m}$, and ratio of the diameter is equal to $1 / 10$. Also, the length of the blade is equal to $2.25 \mathrm{~m}$ according to (Bir et al. 2011), in addition to hub diameter is equal to 0.5 , and the airfoil profile that selected is NACAS809.

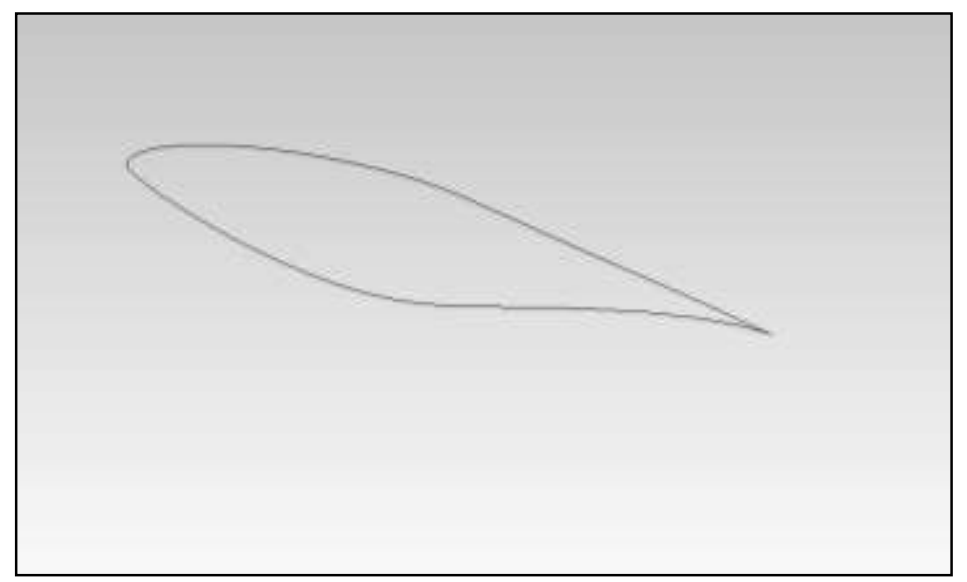

Figure 13: blade profile of NACAS809 (Bir et al. 2011)

The blades contains airfoils as well as tapering thickness in order to conciliate structural and aerodynamic requirements. Moreover, the airfoils have been selected to increase their efficiency at their attack angles and Reynolds number, as shown in Figure 13.

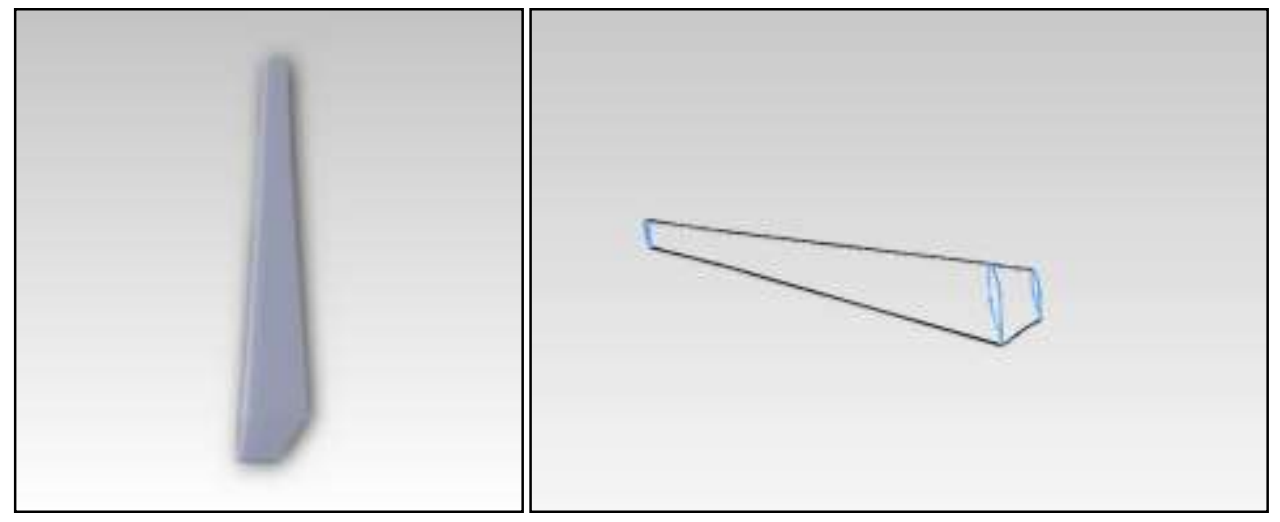

Figure 14: Blade tip design utilizing solid work

Also, the blade tip used a thin airfoil in order to increase ratio of drag and the root zone using a thick airfoil to obtain the structural sustenance. 


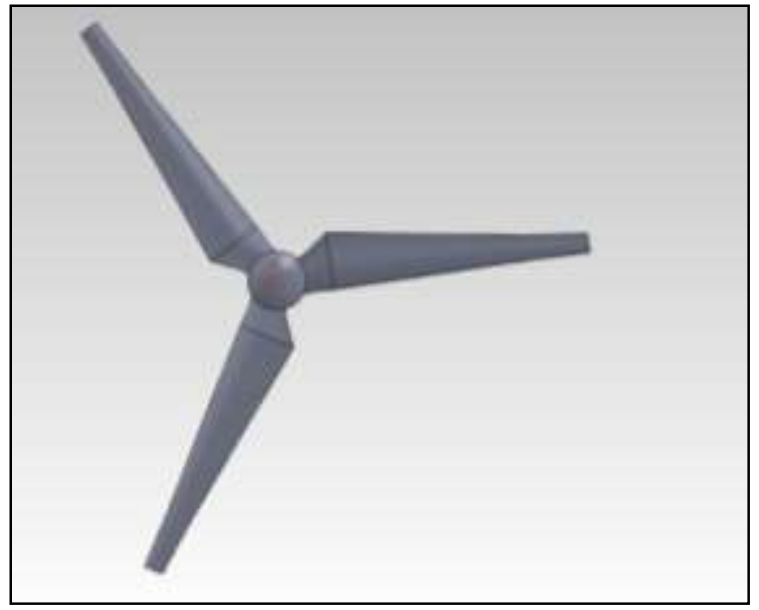

Figure 15: Drawn turbine using solidwork

The turbine rotor diameter is equal to $5 \mathrm{~m}$, and the solid work software was used to design blades with diameter of hub equal to $0.5 \mathrm{~m}$.

\section{Attack Angle}

Solid work is used in this research to design and test the selected blade profile as explained in both Figures 14 and 15. Then, ANSYS workbench was used to export the profile. In addition, the CFD fluent in was utilized in order to test the chosen profile within range of (0-14) for attack angles.

Figure 16 explains the results of capturing velocity distribution, and illustrates the velocity magnitude at at zero attack angle over the selected profile, where the maximum value of speed is equal to $0.34 \mathrm{~m} / \mathrm{s}$ that is consedered smaller than the implemented speed current of $(0.369 \mathrm{~m} / \mathrm{s})$ thus the value of TSR will be equal to 0.921 .
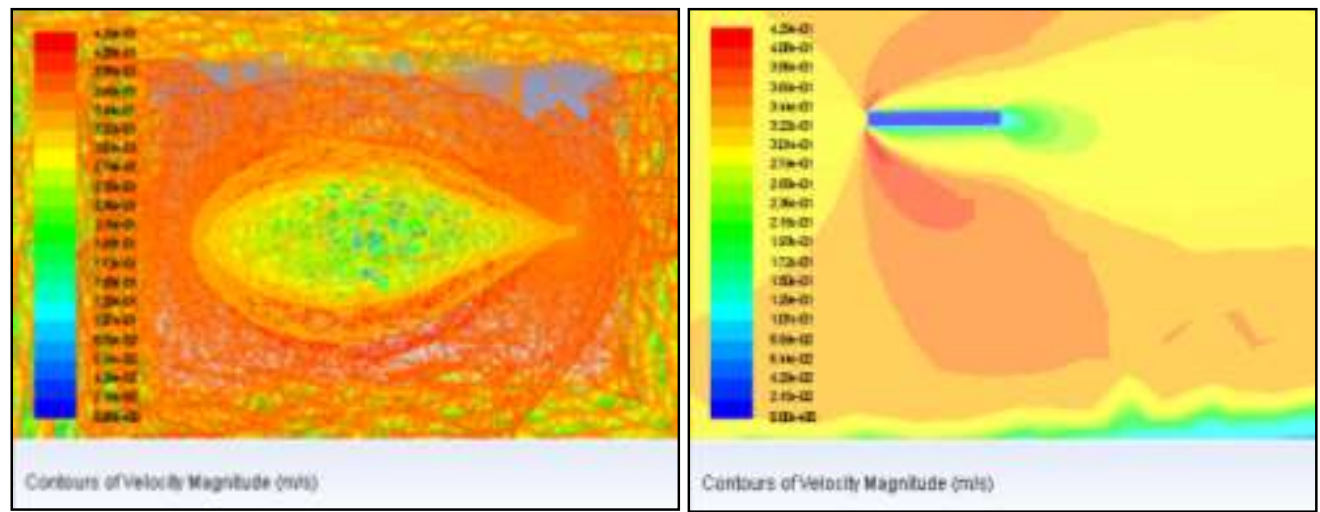

Figure 16: Magnitude of velocity zero attack angle

The magnitude of velocity at $(\alpha)$ equal to 10 has been observed, where the maximum value of velocity is $0.38 \mathrm{~m} / \mathrm{s}$, which is considered smaller than the implemented velocity, which is equal to $0.369 \mathrm{~m} / \mathrm{s}$. So, the value of TSR will be 1.029 , where it can be seen that there is a proportional relation between TSR and attack angle. 


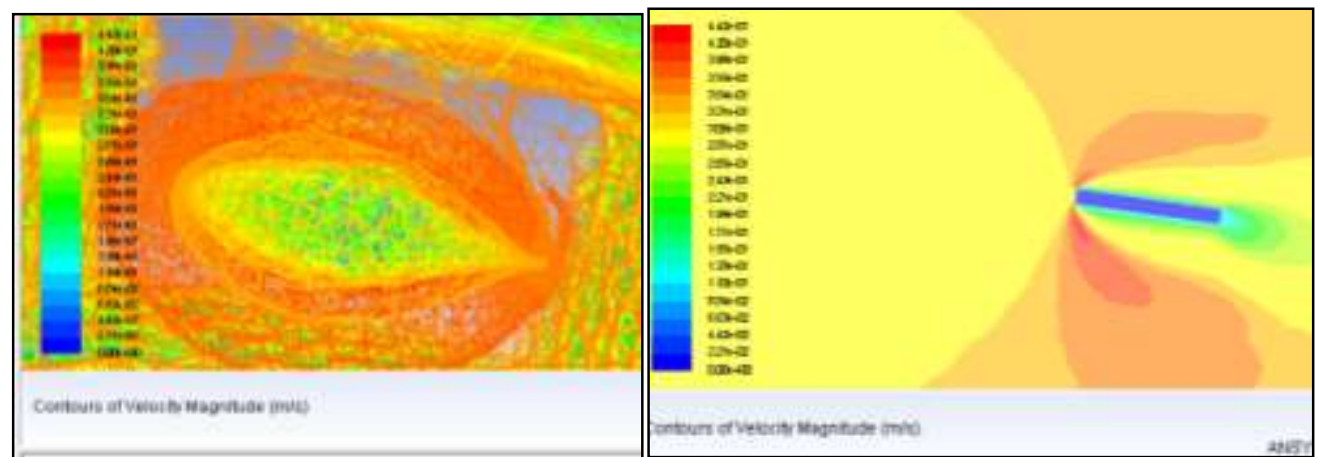

Figure 17: Magnitude of Velocity at 10 attack angle

As shown in Figure 18, 14 degree is the value of attack angle where the impact is occured, where the maximum velocity was $0.4985 \mathrm{~m} / \mathrm{s}$ that is larger than the implemented velocity thus the TSR value is 1.38 . So, it can be said the TSR valuewill increase with increasing value of attack angle.
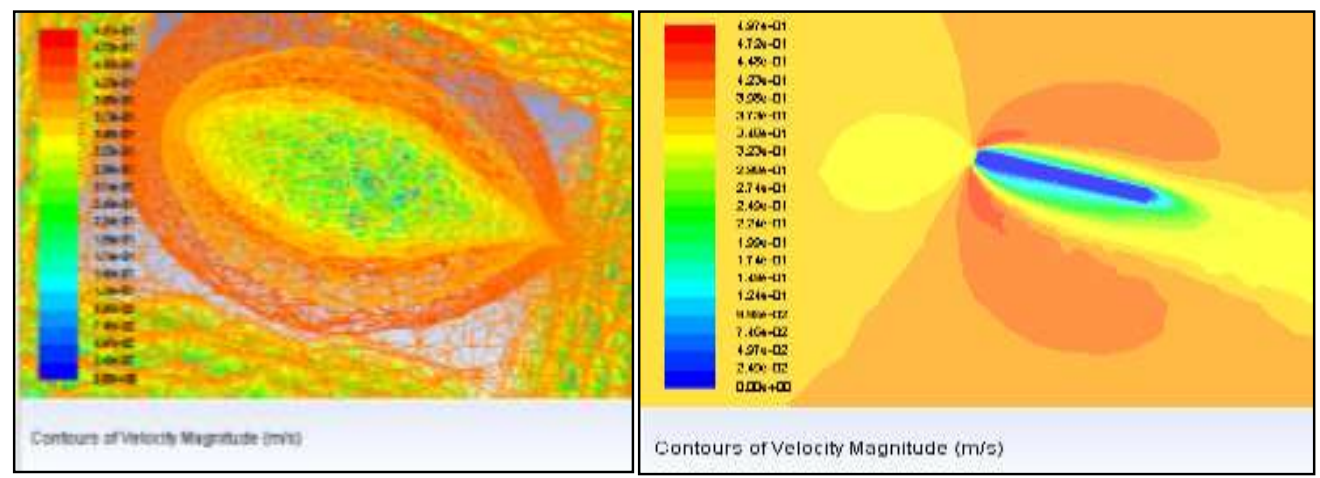

Figure 18: Magnitude of Velocity at attack angle is 14

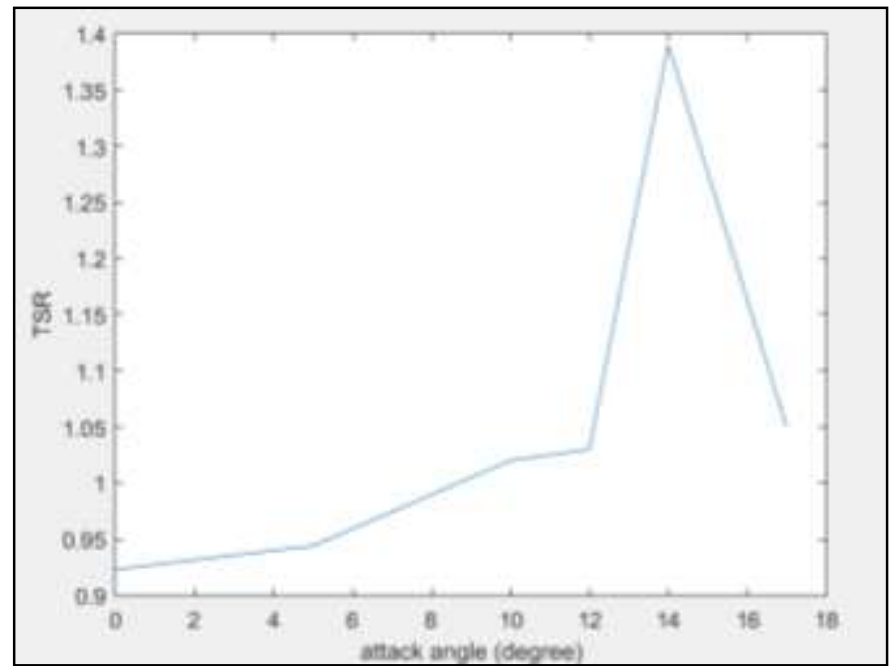

Figure 19: Tip speed ratio (TSR) 
As shown in Figures 19, it is a clear that (14 degree) can be considered as the best value of attack angle, which gives the required value of TSR ratio without risk that equal 1.4. Moreover, the conducted tests illustrate that at 14 degree, hydrodynamic execution is better in terms of turbine drag power coefficients.

\section{Selection process for Diffuser}

A diffuser is installed into the tidal turbine to increase the current velocity, the diffuser can be considered as amplifier, which is utilized in order to raise up the velocity current leading to increase the generated power, where the chosen diffuser is shown in Figure20.

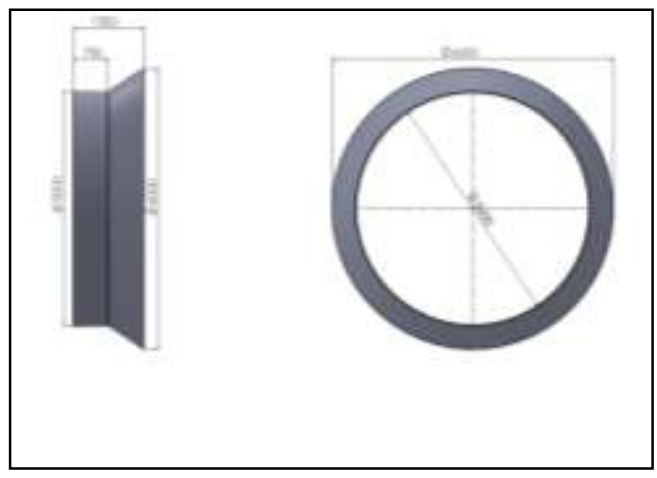

a)

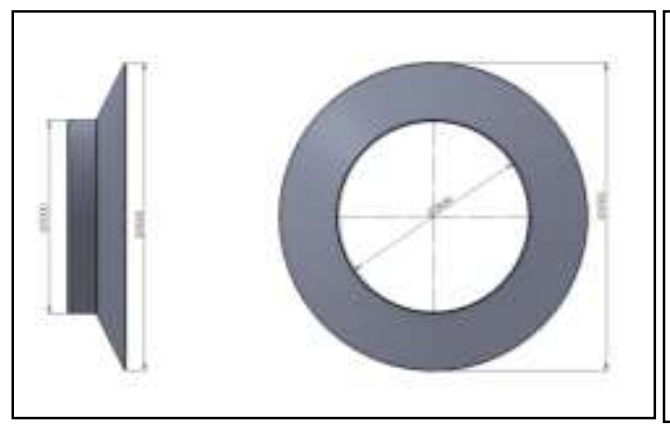

c)

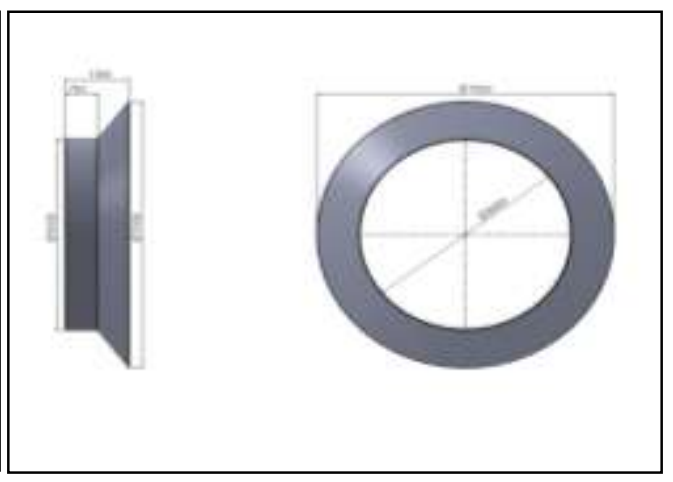

b)

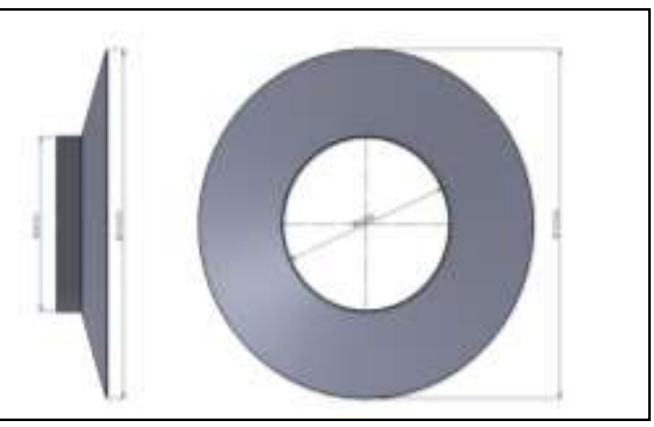

d)

Figure 20: The diffuser profile at different AO/AI; 1.2, 1.4, 1.8 and 2 respectively

Power coefficient (Cp) in addition to TSR should be taken into consideration for highest performance of diffuser. Also, the diffuser must be corresponding with (TSR).

By dividing $(\mathrm{AO})$ on the $(\mathrm{AI})$ the result will be as the following:
a) $1.2=\frac{\mathrm{AO}}{\mathrm{AI}}$
b) $1.4=\frac{\mathrm{AO}}{\mathrm{AI}}$
c) $1.8=\frac{\mathrm{AO}}{\mathrm{AI}}$
d) $2=\frac{\mathrm{AO}}{\mathrm{AI}}$ 


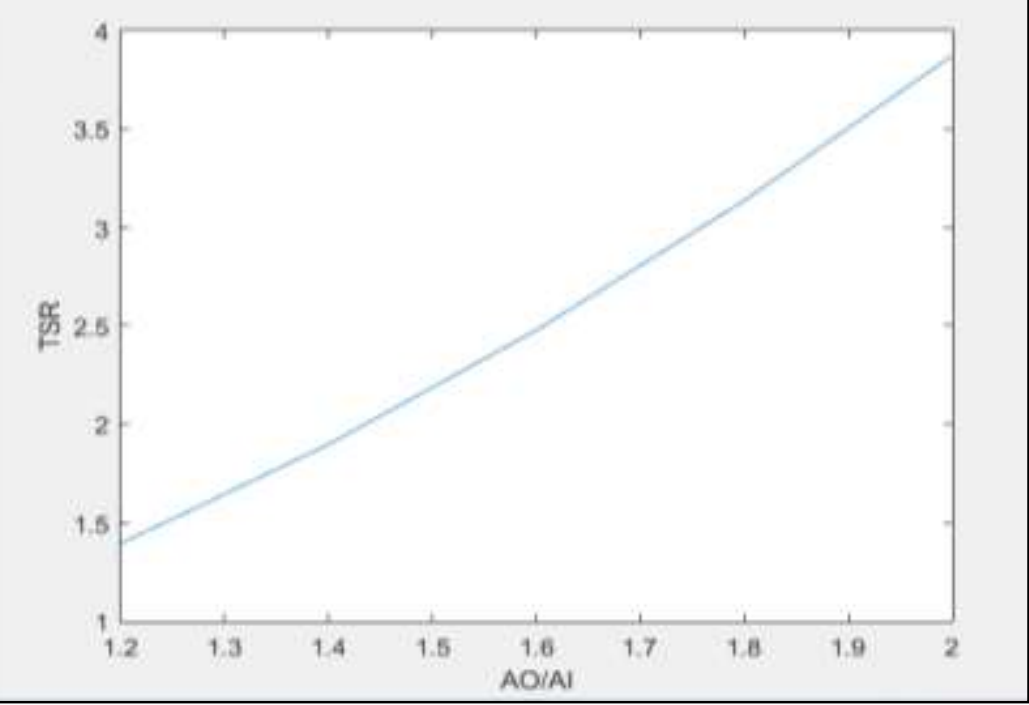

Figure 21: TSR at different diffuser

As illustrated in Figure 21, the velocity distribution was observed at $\mathrm{AO} / \mathrm{AI}=2$. The diffuser value of 1.2 is compatible with TSR value of 1.4, and the 1.4 value of diffuser is compatible with 1.7 value of TSR. Also, 1.8 for diffuser is also compatible with 3 of TSR, and diffuser value of 2 is compatible with TSR of 3.8 that is considered as the biggest value of TSR. Figure 22 explains the proportional relation between TSR and AO/AI.

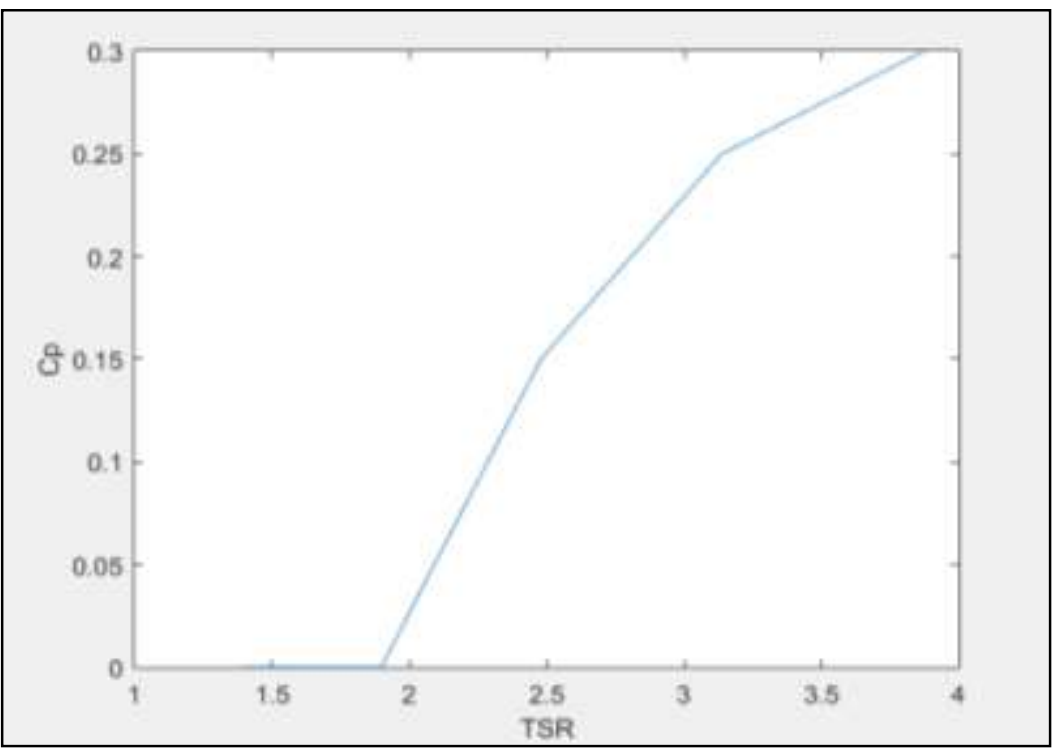

Figure 22: TSR with CP for the selected diffuser

Theoretically, the maximum value of efficiency for all turbine layouts is restricted to be $0.59 \%$, which referred to maximum CP value (CP max $=0.59)(\mathrm{Li}$ and Calisal, 2010), where Figure 22 shows that value of TSR increases with increasing value of Cp. 


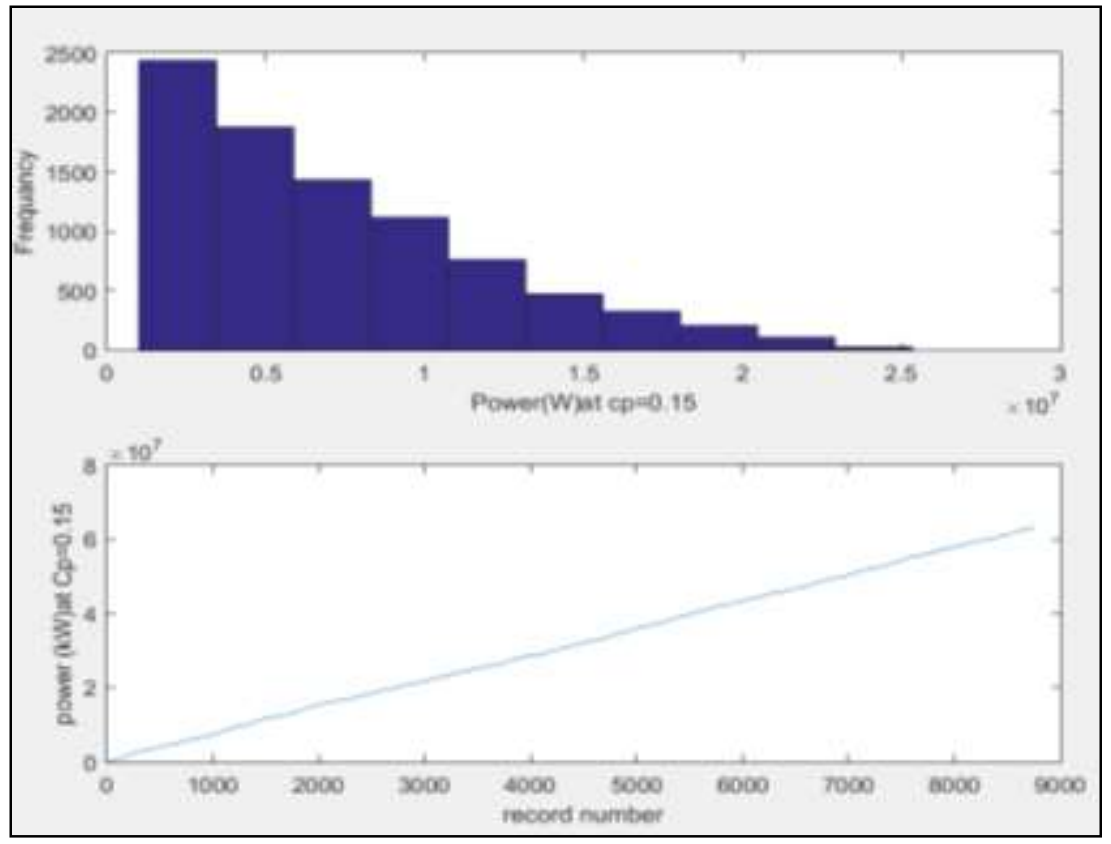

Figure 23: kinetic energyand Frequency distribution at $\mathrm{Cp}$ of 0.15

Where Figure 23shows how the frequencies of the measured power are distributed at $\mathrm{Cp}=0.15$.

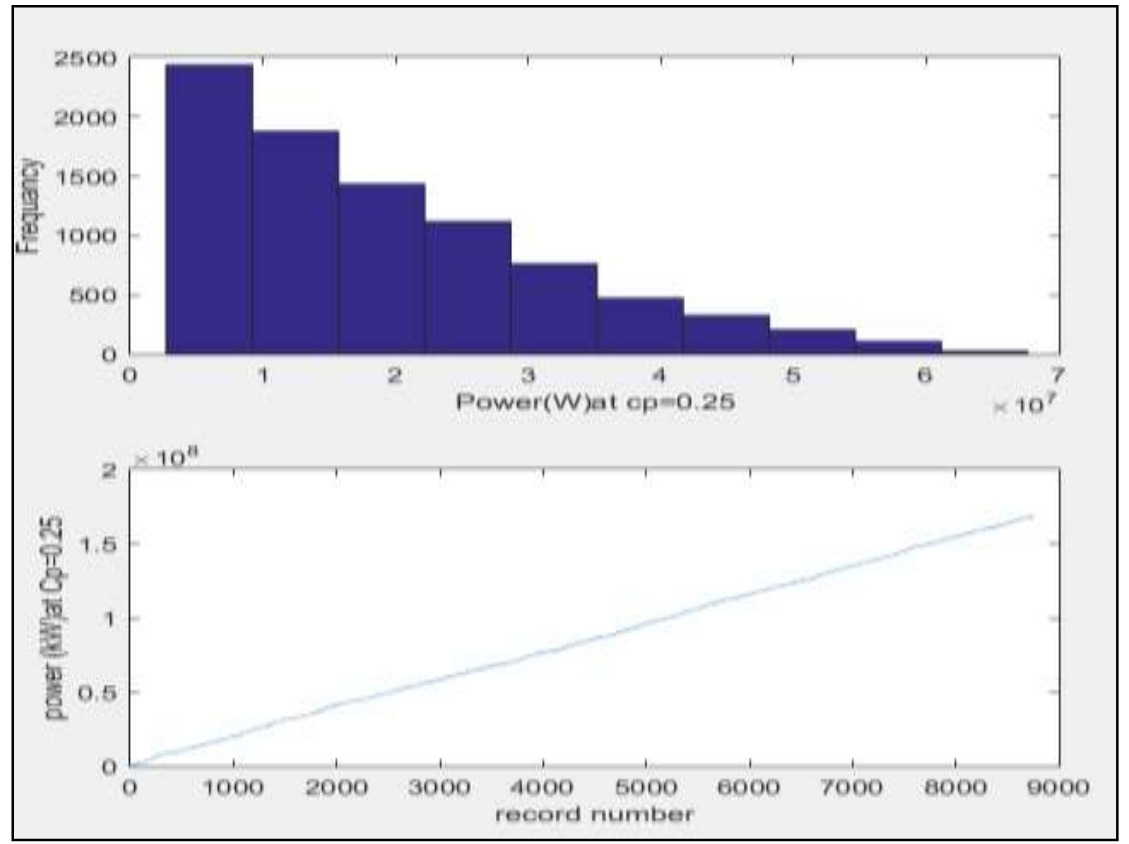

Figure 24: kinetic energy and Frequency distribution at $\mathrm{C} p=0.25$

Figure 24 shows values of the power that are measured in $\mathrm{kW}$ and frequency at value of $\mathrm{Cp}$ that equal to 0.25 to show the effect of $C p$ value on frequency. 


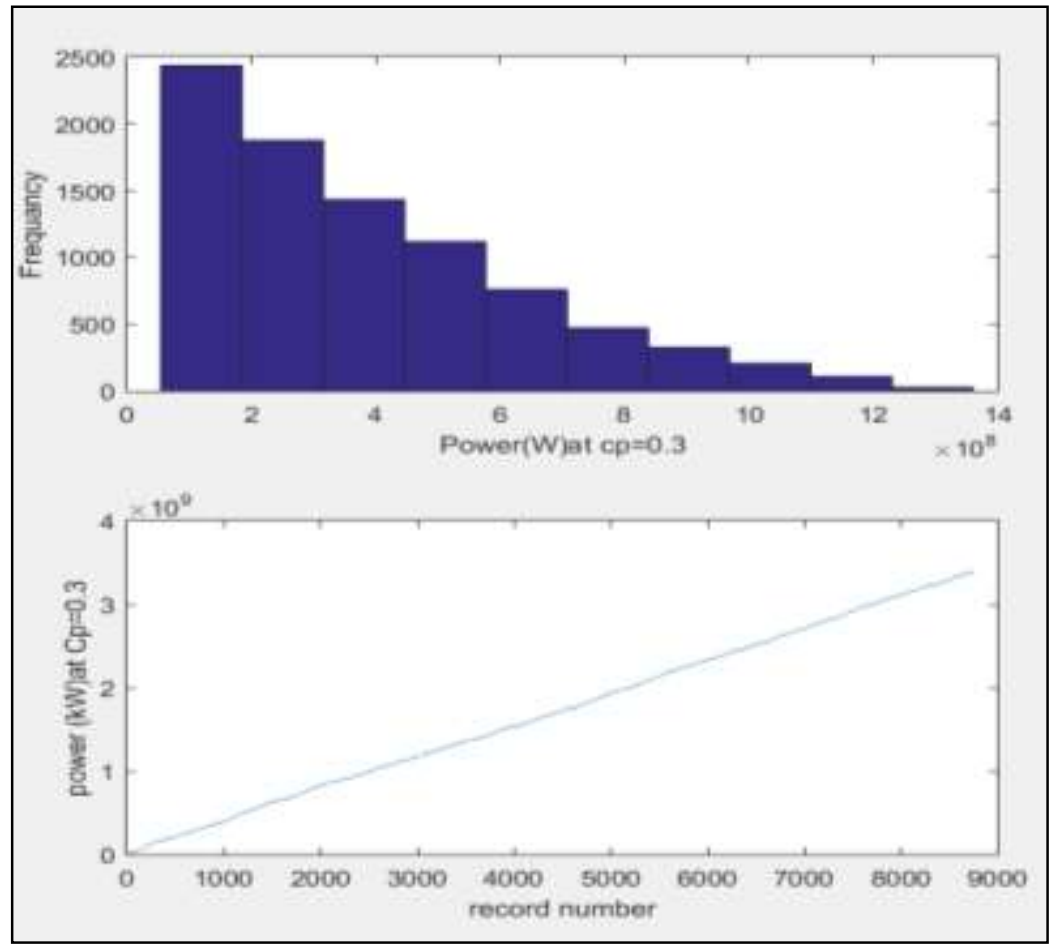

Figure 25: kinetic energy and frequency distribution at $\mathrm{Cp}=0.3$

The value of $\mathrm{Cp}$ is varied to be 0.3 in order to show its effect on the frequency distribution. Figure 25 shows the proportional and linear relation between recorded number the power.

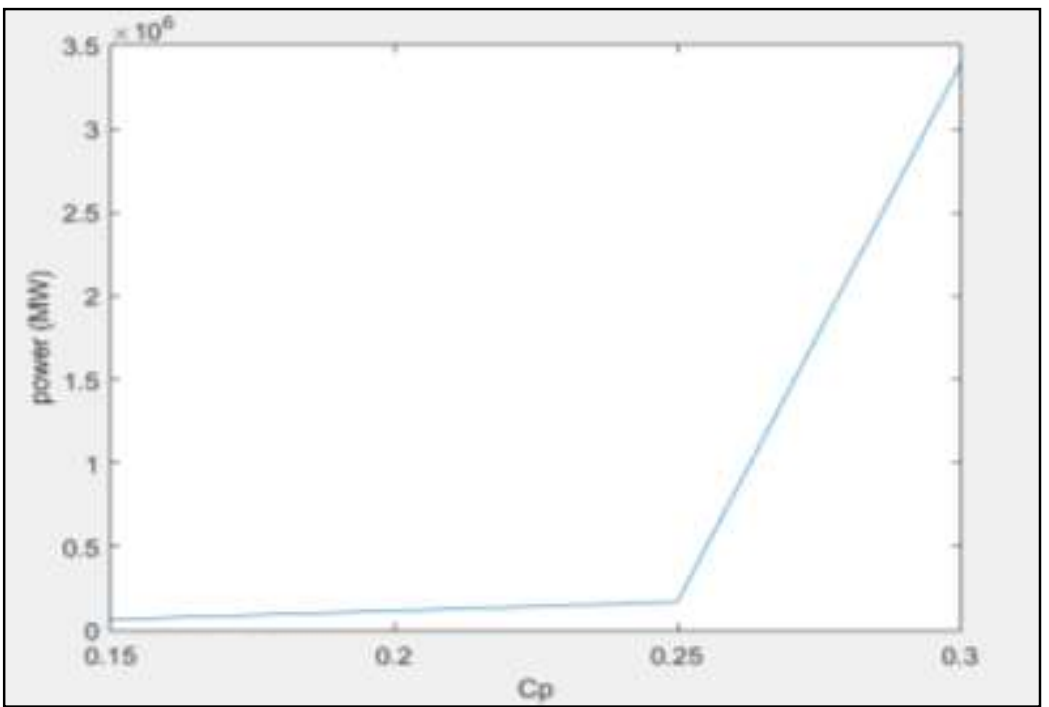

Figure 26: Relation between power and $\mathrm{Cp}$

From Figure 26, it is clear that the occurred change $\mathrm{Cp}$ value effect on the power, and the perfect $\mathrm{Cp}$ value is 0.3 that is corresponds the maximum power of $3.5 \mathrm{Mw}$ for the second location. 


\section{Capturing of Power}

This section introduces the type and the amount of generated tidal turbine power. In fact, the generated power by tidal turbine strategy is initially a mechanical power and it is exchanged to produce electrical power using the generators. The generated mechanical power from the tidal turbine at diverse numbers of records is shown in Figure 27. KW is used to measure mechanical power with highest mechanical power approximately equals $200 \mathrm{KW}$.

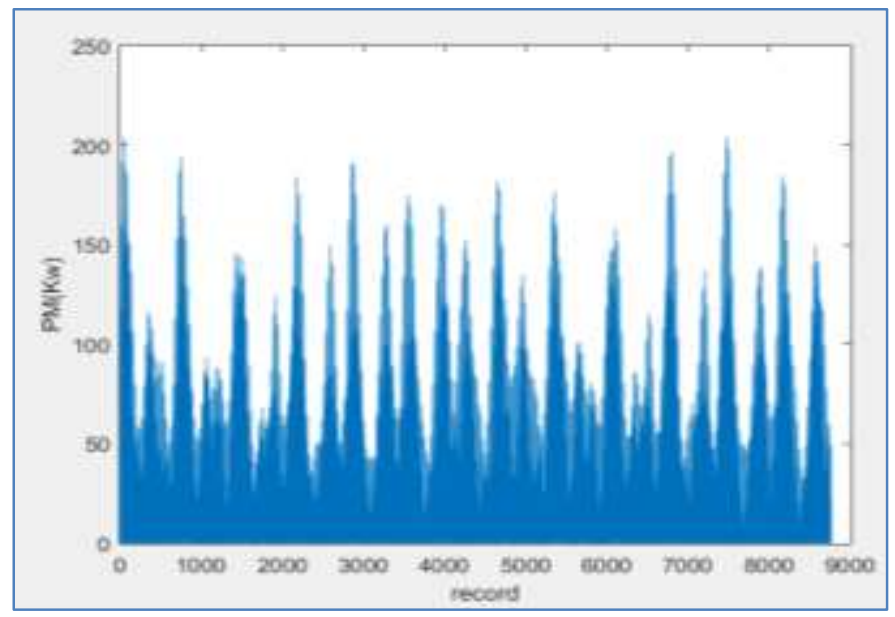

Figure 27: Generated Mechanical power via tidal turbine

Figure 28 illustrates the average of generated mechanical power via the wind turbine measures in $\mathrm{kW}$ at diverse velocities flow that in turns measured in $\mathrm{m} / \mathrm{s}$. Figure 28 shows that the generated power amount raised with increasing the flow velocity, the maximum generated power amount is achieved at flowvelocity $=3.8 \mathrm{~m} / \mathrm{s}$.

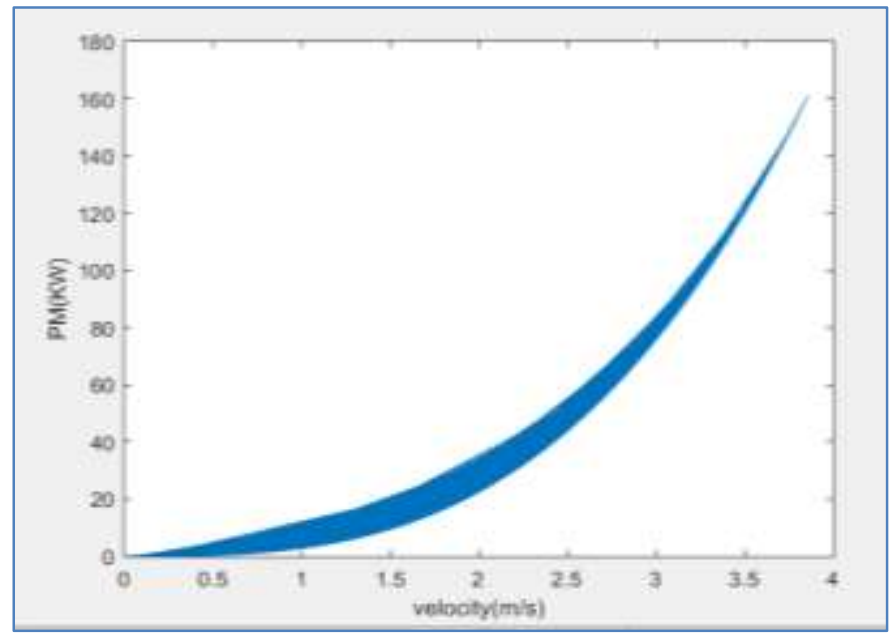

Figure 28: Average Mechanical power produced via tidal turbine at diverse velocities of flow

As stated by earlier study, electricity can be produced by the clean turbine with $50 \%$ efficiency. Considering 50\% efficiency, Figure 29 illustrates the electrical power generated in $\mathrm{KW}$ in terms of the velocity. 


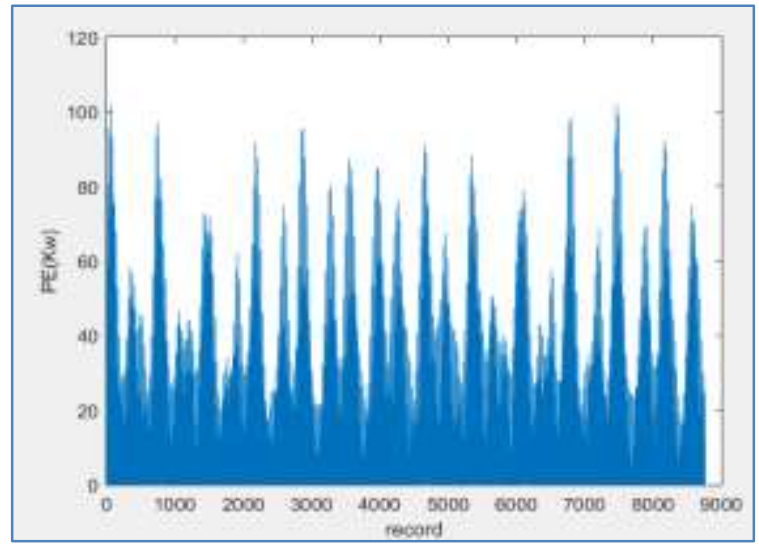

Figure 29: Produced Electrical power via tidal turbines at diverse velocities

The average generated electrical power measured in $\mathrm{Kw}$ at different velocities measured in $\mathrm{m} / \mathrm{s}$ is illustrated in Figure 30. It is obvious that the generated electrical energy increases with the velocity. The maximum generated amount of electrical energy equals $100 \mathrm{Kw}$ achieved at velocity $=3.8 \mathrm{~m} / \mathrm{s}$.

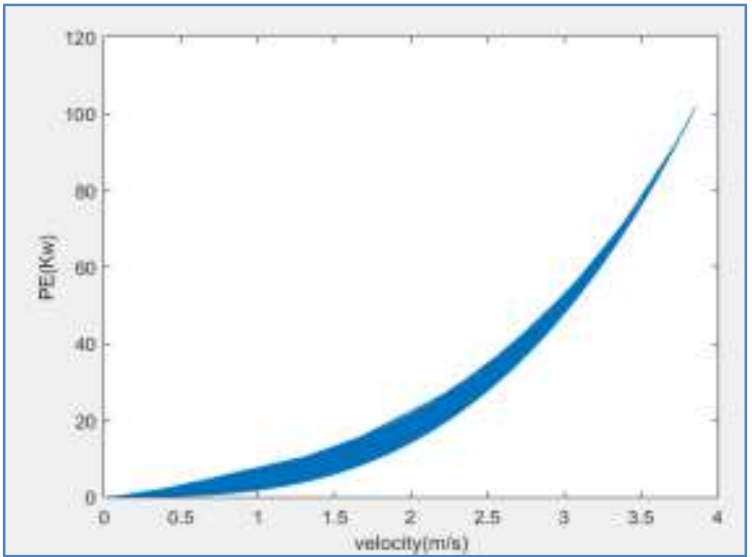

Figure 30: Average electrical power at diverse velocities

\section{Design of Tidal Turbines Farm}

Figure 31 shows the farm's dimensions and tidal turbines' distribution.

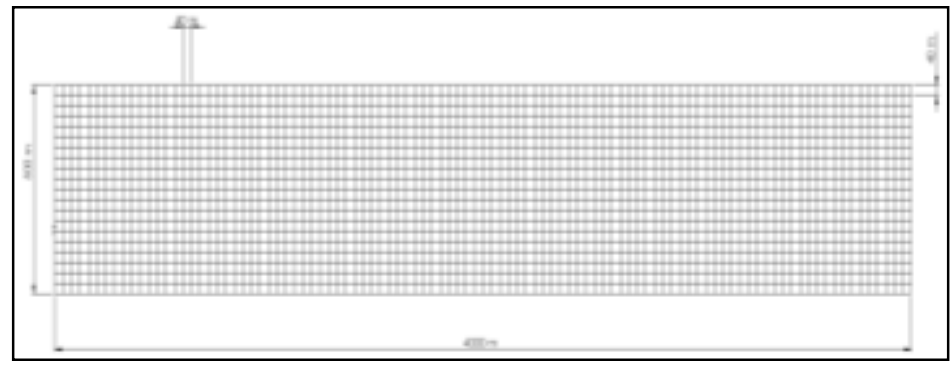

Figure 31: The dimensions of the intended farm 
The plan of the farm was chosen to be built within vertical array to the tides direction. Based on the recorded data by KISR, the average tidal angle is 239 degree. Consequently, the tidal turbines are supposed to be distributed within vertical representation with the average. Figure 32 illustrates the farm turbines distribution and the coordination of each one of the turbine.

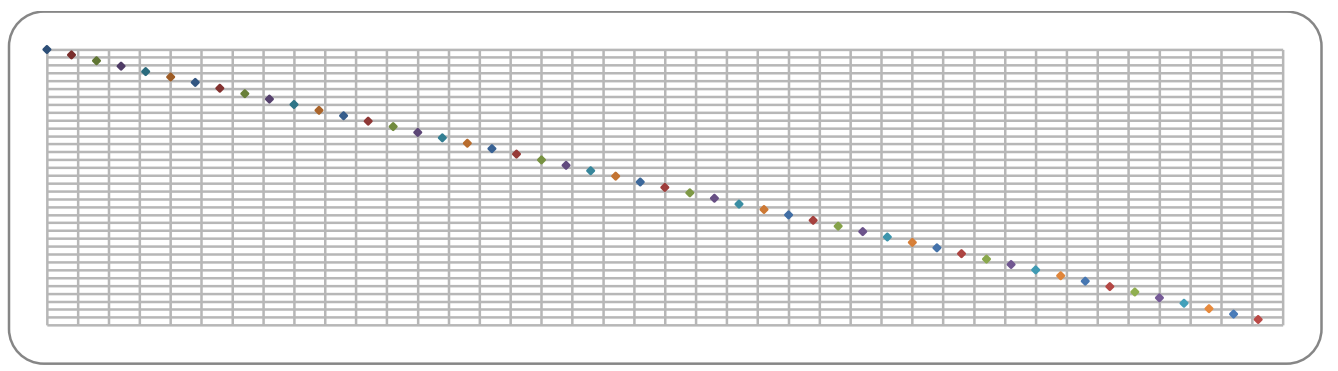

Figure 32: Tidal turbines Distribution within the farm

\section{Connecting Turbine with the Grid Electrically}

The tidal current turbine grid-connection can be introduced based on the worldwide system as given and illustrated below in the following figure. In general, the turbines electrical components can be linked with the substation using LV or MV cables as shown below in Figure 33.

According to Figure 33, the tidal currents initially goes through the blades of the tidal turbine that are moved as a result of currents flow and because the tides kinetic energy is exchanged to mechanical power. Furthermore, the electrical energy obtained from mechanical energy while it goes into the side of the converter and goes through the grid.

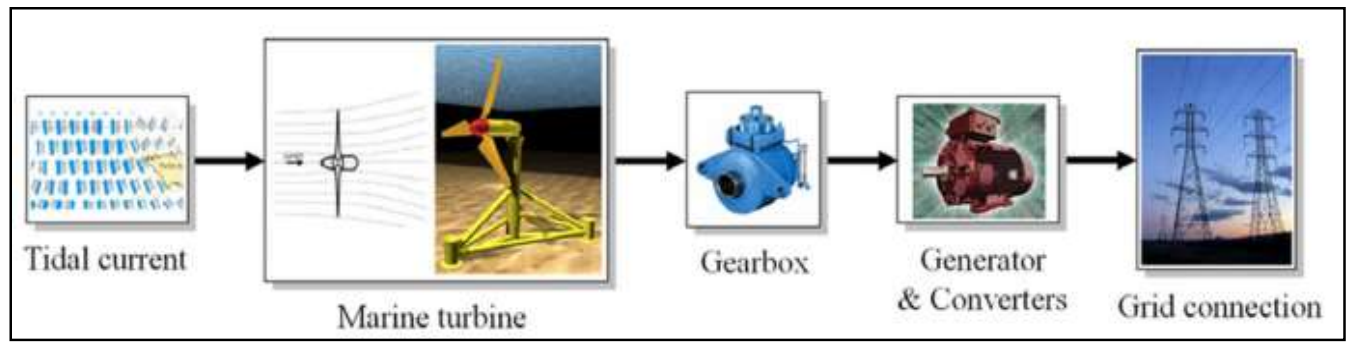

Figure 33: The tidal current turbine components (Bansal and Zoba, 2011)

Both of the mechanical and electrical systems are considered to be synchronous generators. By gear-box exploiting, the bridge of the diode is employed for producing DC voltage.

As stated early, the electrical elements may be connected through cables that are fabricated from different ropes. In general, the traditional rope materials may be fabricated using steel wire or synthesis fiber. Since that the steel wires characterizes with a high strength, they typically employed in anchor chain production. Furthermore, the min undersea platforms are not appropriate to be employed; since they characterizes with high density, which is undesired to the resilience particularly for the deep-sea structures and for the additional pontoons that should be employed within floating platforms. In addition, the steel characterizes with bad decay resistance that raises the required costs for system components. The engineers search for different substitution materials to avoid the mentioned drawbacks for steel as the synthesis fiber. 


\section{Feasibility Study}

This section introduces the likelihood of building tidal turbines farm in Kuwait city, and the needed factor that is essential for measuring the feasibility to build this farm are illustrated below.

The predictable cost for the installation of every turbineis $\$ 2,500 / \mathrm{kW}$. The needed cost for producing tidal power is about $\$ 0.04 / \mathrm{kWh}$ (Renewable Northwest Project RNP, 2017). The cost for generated tidal power turbines was matched up to with the required cost for establishing and producing power using steam electrical power or gas turbines that are used in Kuwait.

Thermal station of Subiya has been constructed recently in Kuwait city and it faraway 17 $\mathrm{KM}$ from the location of this project as illustrated in figure below. The required cost for generating turbine is $\$ 900$ based on the energy specification of United State. Additionally, the goal from building the thermal station of Subiya is producing energy with approximately quantity equal to $2400 \mathrm{MW}$. The overall cost of the project is $\$ 2.2$ billion, or $\$ 916$ per each KW based on (Power Technology Company). Furthermore, the predictable cost needed to produce electricity is $\$ 0.13$ / $\mathrm{kWh}$ (Water and Electricity Ministry-Kuwait). The distance among the selected location and Subiya thermal station are illustrated below in Figure 34.

The required number turbines in the location of the project is equal to 160 turbine to meet the mandatory demand based on the standard generation for the average power. In addition, this required number of turbines is expensive and huge, so the goal from the viability and evaluation among the available types stated early is to determine the suitable turbines number that can meet the needed power.

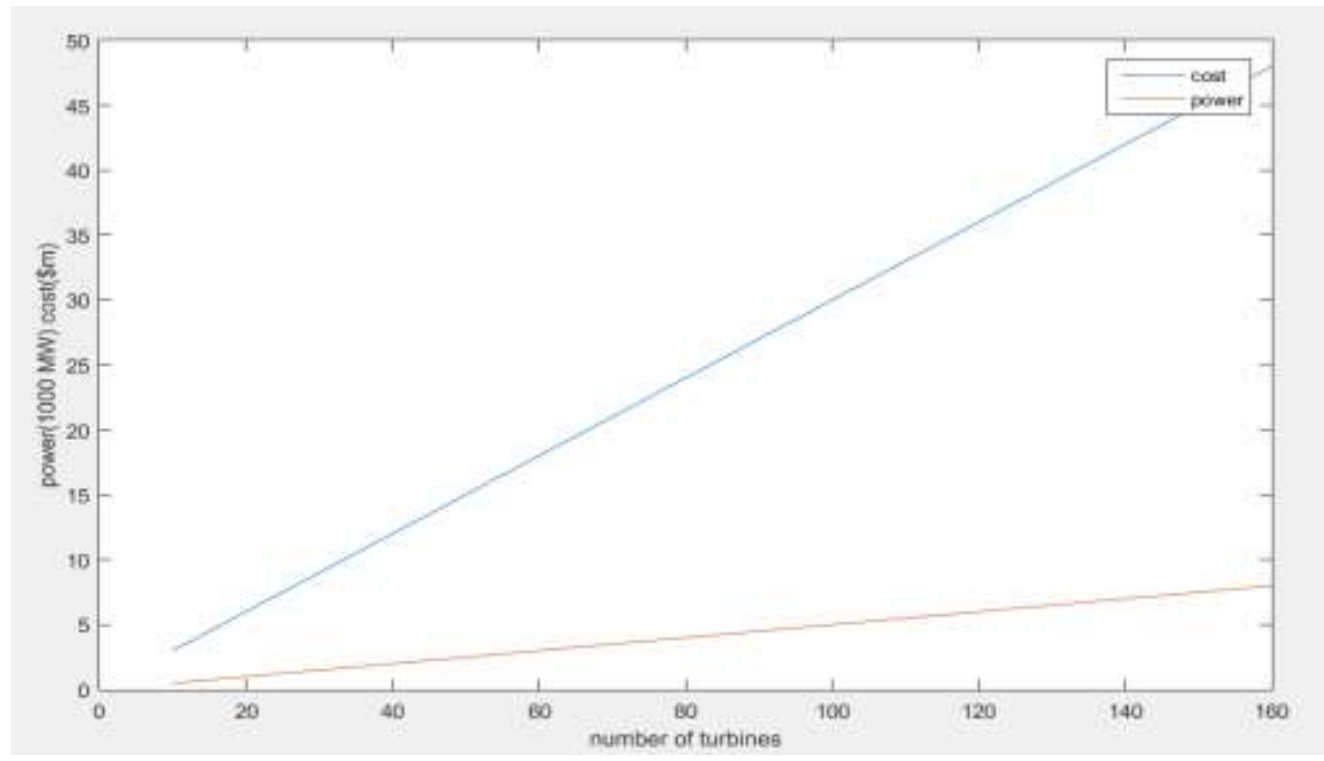

Figure 34: Output power and cost of installation versus turbines number

The operation cost per each year for the capital investment and the turbines number are considered as a pointer for the overall investment cost that can be predicted based on the summation of the capital investment and cost of operation per each year. 


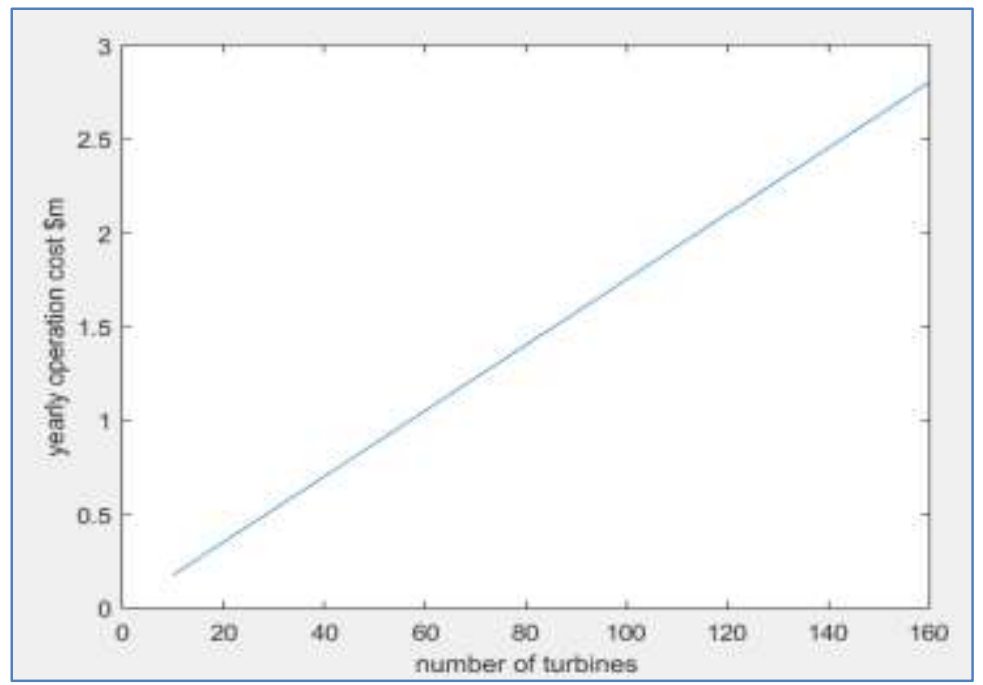

Figure 35: the operation cost versus turbines number

An important and crucial factor that must be carefully planned is the period of payback that can be expected for the turbine by means of diverse numbers such as; 10,30 and 50 as shown below in the next figure. The designed number of turbine is selected to be 50 turbine considering2.5 MW of average power and through main investment about $15 \$ \mathrm{~m}$ and yearly cost of operation up to $876,000 \$$. The predictable period of payback that required for establishing 50 tidal turbines was estimated to be 6 years with a yearly profit of $2.847 \$ \mathrm{~m}$.

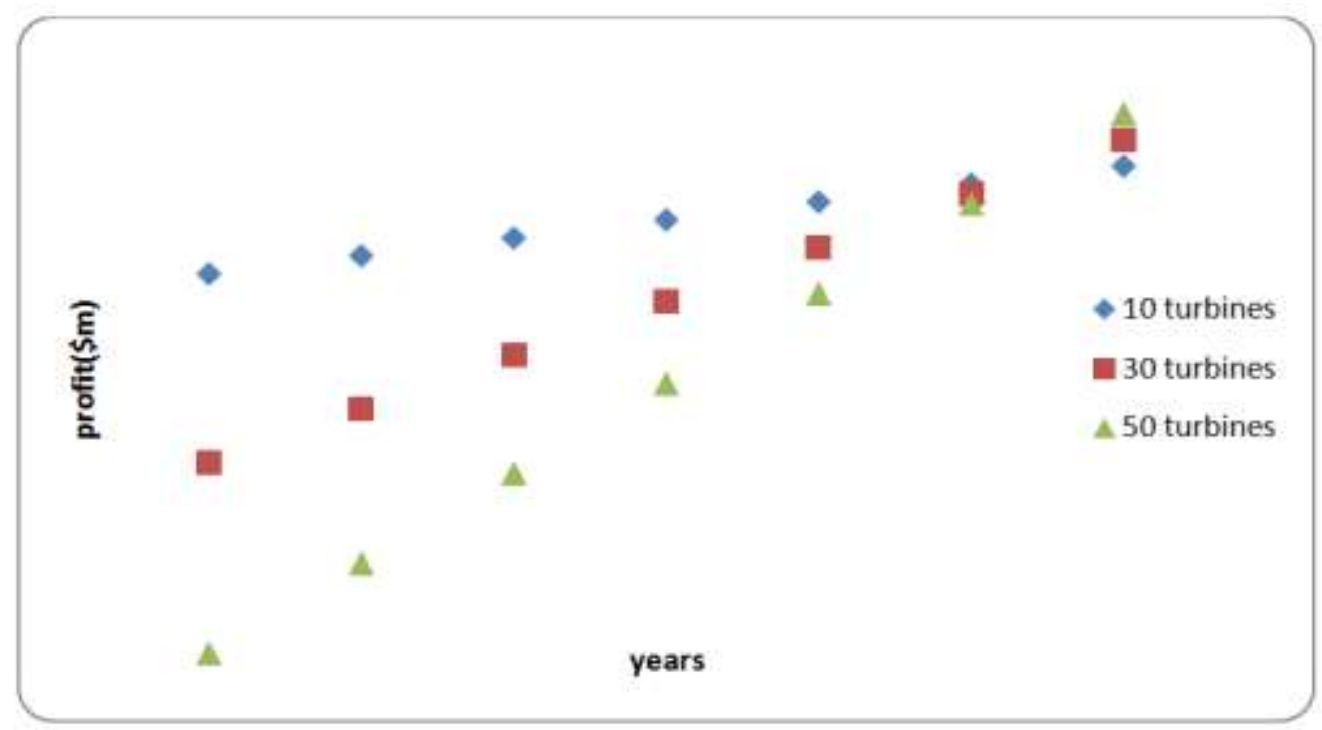

Figure 36: The period of payback for diverse turbines number

There are different factors that affect the power plant, in Figure 37, a comparison between the produced power of dismissal oil cost and the cost of produced farm's power is illustrated. However, the cost of the capital investment for the oil of firing plant is less than the cost of tidal farm based on the particular infrastructure necessity for the construction of 
tidal farm, such as; grid connection, the building, a small number of suppliers, and the chosen site connection. Additionally, the cost of operation for the tidal farm is less than the oil-fired plants according to the cost of fuel that will be vital for plants operation. Furthermore, as illustrated in Figure 37, the cost of annual operation for the tidal farm is approximately $876,000 \$$ compared with $2.87 \$ \mathrm{~m}$ for the oil of firing needed for producing similar power amount.

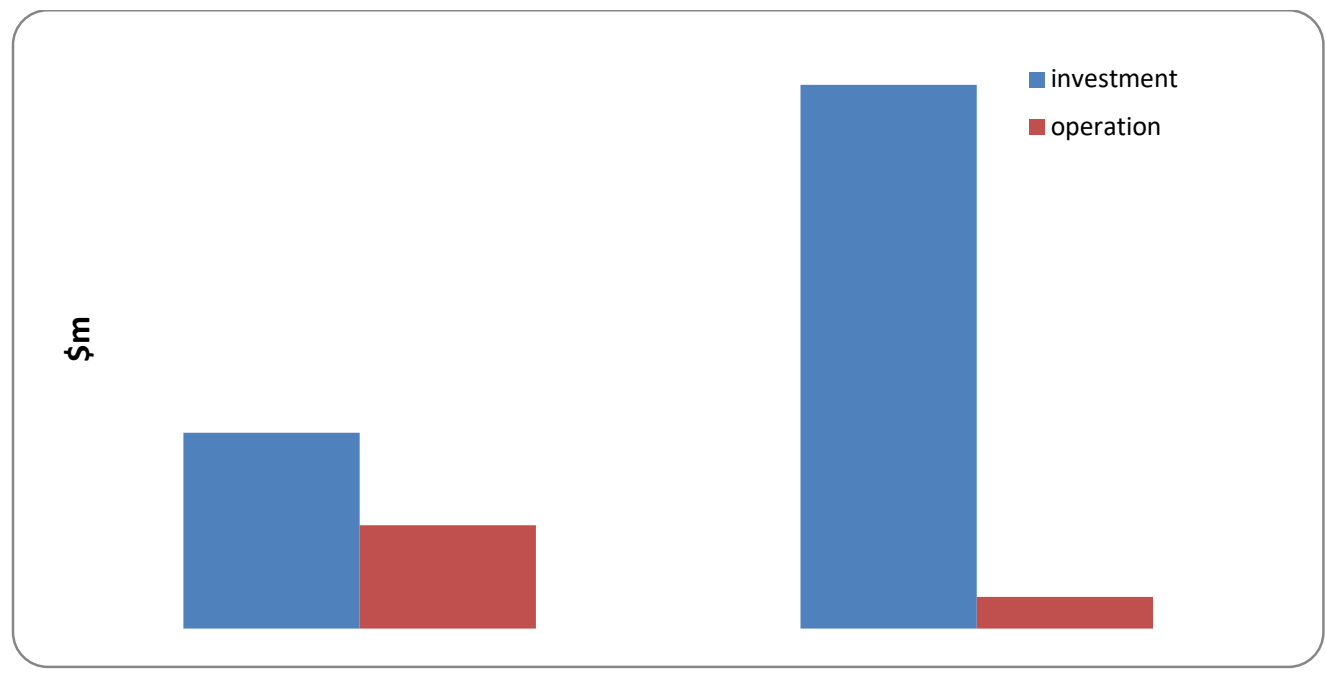

Figure 37: Comparison of the cost between tidal and oil firing

Another drawback for tidal farm is the reduction of emissions compared to fired plants of oil. The predicted quantity for each KWh is approximately $1.76 \mathrm{lb}(0.798 \mathrm{Kg})$ ("US Energy information administration", 2016) of $\mathrm{CO}_{2}$. This in turns means that the emission quantity of $\mathrm{CO}_{2}$ is about 17476.2 ton that will be created from the oil-fired plants, and this passion will be removed by using tidal farm.

\section{CONCLUSION}

The energy of tides waves depends primarily on two main force's components, particularly; kinetic energy and potential energy. The potential energy is referred to the work made via elating the water mass higher than the surface of the occean. There are different features for exploiting tides energy for generating electricity. The most significant and critical two of them are; ecological circumstances refinement and green revivals influence lowering.

The analysis results in this paper illustrate that utilizing the fossil fuel stills an essential requirement to satisfy energy requirements of the market and to get more enlargements within energy field achieved on cooperation on the environment and the habitats health. Additionally, renewable energy is increased within the world to be employed considerably as the trends are changeable with more appropriate renewable policies. Furthermore, the numbers of projects for renewable energy or employing clean energy amount is small in Middle East or not exist compared to the worldwide scale. According to the arithmetical Review that is introduced via BP about globe energy throughout 2015, the production quantity of Middle East for renewable energy is just $0.1 \%$ of the overall globe renewable energy. However, the increase percentage in the renewable energy amount within Middle East is equal to $47 \%$ with overall negligible production. Furthermore, there is a large 
possibility for exploiting the resources of renewable energy resource in Middle East to meet the energy insists, especially the solar energy that is significantly supported in Middle East. Tidal power plants are being built in several places all over world. Actually, MENA region stills requires to tidal power plant, where the merely recorded tides power plant is the established one by WERPO Israeli Company.

\section{REFERENCES}

Al-Ammar E. A., Malik N. H., and Usman, M. (2011) Application of Using Hybrid Renewable Energy in Saudi Arabia, ETASR - Engineering, Technology \& Applied Science Research, 1(4):84-89.

Li, Y. \& Calisal, S. (2010). Three-dimensional effects and arm effects on modeling a vertical axis tidal current turbine. Renewable Energy. 35. 2325-2334. 10.1016/j.renene.2010.03.002.

Bansal R., and Zoba A. (2011) Handbook of renewable energy technologies, World Scientific Publishing Company.

Bir G.S., Lawson M. J., and Li Y. (2011) Structural Design of a Horizontal-Axis Tidal Current Turbine Composite Blade, National Renewable energy laboratory (NREL).

Brinck D., and Jeremejeff N. (2013) The development of a vertical axis tidal current turbine, KTH School of Industrial Engineering and Management.

Etemad A, Emami Y., and Emdadi A. (2011) Electricity generation by the tidal barrages, Maxwell Scientific Organization.

Fraenkel P. (2010) Development and testing of marine current turbine's SeaGen 1.2MW tidal stream turbine, International conference on ocean energy.

Gilany M. (2001) Tidal Power Generation Systems, the American University in Cairo Engineering Department.

Gorji-Bandpy M., Azimi M., and Jouya M. (2013) Tidal Energy and Main Resources in the Persian Gulf, Distributed Generation and Alternative Energy Journal, 28 (2) pp: 61-74.

Goundar M., and Ahmed M. (2013) Design of a horizontal axis tidal current turbine, Applied Energy.

Gray T. (1970) Tidal Power Proceedings of an International Conference on the Utilization of Tidal Power, Atlantic Industrial Research Institute.

Howell R., Qin N., Edwards J., and Durrani N. (2011) Wind tunnel and numerical study of a small vertical axis wind turbine, Elsevier, Vol. 35. 0960-1481.

International Energy Agency (2014) World energy investment outlook, IEA.

International Energy Agency (2013) World Energy Resources, IEA.

Khalid S. Sh., Liang Z., and Shah N. (2012) Harnessing Tidal Energy Using Vertical Axis Tidal Turbine, Research Journal of Applied Sciences, Engineering and Technology, 5(1), pp: 239-252.

Khalid S., Liang Zh., and Shah N. (2013) Harnessing Tidal Energy Using Vertical Axis Tidal Turbine, Maxwell Scientific Organization.

Lee J. H., Park S., Kim D. H., and Rhee SH. (2013) Computational methods for performance analysis of horizontal axis tidal stream turbines, Energy, 98:512-23.

Statistical Review (2015) BP Statistical Review of World Energy.

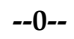

DOI: https://doi.org/10.18034/ei.v6i2.229

Online Archive Link: https://abc.us.org/ojs/index.php/ei/issue/archive 